University of South Florida

DIGITAL COMMONS

Digital Commons @ University of

@ UNIVERSITY OF SOUTH FLORIDA

South Florida

KIP Articles

KIP Research Publications

January 2015

\title{
Luminescence dating of fluvial deposits in the rock shelter of \\ Cueva Antón, Spain
}

Burow Christoph

Martin Kehl

Alexandra Hilgers

Gerd-Christian Weniger

Diego E. Angelucci

See next page for additional authors

Follow this and additional works at: https://digitalcommons.usf.edu/kip_articles

\section{Recommended Citation}

Christoph, Burow; Kehl, Martin; Hilgers, Alexandra; Weniger, Gerd-Christian; Angelucci, Diego E.; Villaverde, Valentín; Zapata, Josefına; and Zilhão, João, "Luminescence dating of fluvial deposits in the rock shelter of Cueva Antón, Spain" (2015). KIP Articles. 3251.

https://digitalcommons.usf.edu/kip_articles/3251

This Article is brought to you for free and open access by the KIP Research Publications at Digital Commons @ University of South Florida. It has been accepted for inclusion in KIP Articles by an authorized administrator of Digital Commons @ University of South Florida. For more information, please contact digitalcommons@usf.edu. 


\section{Creator}

Burow Christoph, Martin Kehl, Alexandra Hilgers, Gerd-Christian Weniger, Diego E. Angelucci, Valentín Villaverde, Josefına Zapata, and João Zilhão 


\title{
LUMINESCENCE DATING OF FLUVIAL DEPOSITS IN THE ROCK SHELTER OF CUEVA ANTÓN, SPAIN
}

\author{
CHRISTOPH BUROW ${ }^{1}$, MARTIN KEHL ${ }^{1}$, ALEXANDRA HILGERS ${ }^{1}$, GERD-CHRISTIAN WENIGER ${ }^{2,3}$, \\ DIEGO E. ANGELUCCI ${ }^{4}$, VALENTÍN VILLAVERDE ${ }^{5}$, JOSEFINA ZAPATA ${ }^{6}$, JOÃO ZILHÃO ${ }^{7}$ \\ ${ }^{1}$ University of Cologne, Institute of Geography, Albertus-Magnus-Platz, 50923 Cologne, Germany \\ ${ }^{2}$ Neanderthal Museum, Talstraße 300, 40822 Mettmann, Germany \\ ${ }^{3}$ University of Cologne, Institute of Prehistoric Archaeology, Albertus-Magnus-Platz, 50923 Cologne, Germany \\ ${ }^{4}$ Dipartimento di Lettere e Filosofia, Università degli Studi di Trento, via Tommaso Gar 14, 38122 Trento, Italy \\ ${ }^{5}$ Departament de Prehistòria i d'Arqueologia, Universitat de València, Av. Blasco Ibañez 28, 46010 València, Spain \\ ${ }^{6}$ Área de Antropología Física, Facultad de Biología, Universidad de Murcia, Campus Universitario de Espinardo, 30100 Murcia, Spain \\ ${ }^{7}$ Seminari d'Estudis i Recerques Prehistòriques, Departament de Prehistòria, Història Antiga i Arqueologia,
}

Facultat de Geografia i Història, Universitat de Barcelona/ICREA, Spain

Received 5 March 2014

Accepted 6 January 2015

\begin{abstract}
The fluvial sediments at Cueva Antón, a Middle Palaeolithic rock shelter located in the valley of the River Mula (Southeast Spain), produced abundant lithic assemblages of Mousterian affinities. Radiocarbon dates are available for the upper part of the archaeological succession, while for the middle to lower parts chronometric data have been missing. Here we present luminescence dating results for these parts of the succession. Quartz OSL on small aliquots and single grain measurements yield ages ranging from $69 \pm 7 \mathrm{ka}$ to $82 \pm 8 \mathrm{ka}$ with a weighted mean of $72 \pm 4 \mathrm{ka}$ for sub-complexes AS2 to AS5. Equivalent dose estimates from large aliquots were highest and inconsistent with those from single grains and small multiple grain aliquots. This is probably caused by the presence of oversaturating grains, which have been quantified by single grain measurements. Additional post-IR IRSL measurements on coarse grained feldspar give strong support to a well-bleached quartz OSL signal. While independent chronometric control is missing, the results are within the expected age range and support the notion of a rapid accumulation of the fluvial deposits.
\end{abstract}

Keywords: Cueva Antón, Middle Palaeolithic, Luminescence dating, fluvial sediment, single grain dating, post-IR IRSL.

\section{INTRODUCTION}

Cueva Antón is a Palaeolithic rock shelter located in the region of Murcia in Southeast Spain. The several meter thick sedimentary fill is mainly of alluvial origin deposited by the adjoining River Mula (Angelucci et al., 2013) (Fig. 1). Based on early findings during salvage

Corresponding author: C. Burow

e-mail: christoph.burow@uni-koeln.de excavations in 1991, where Middle Palaeolithic occupations were identified at the basal levels of the alluvial succession (Martínez, 1997), more recent fieldwork between 2006 and 2012 gave evidence that human occupation also occurred during the accumulation of the upper parts of the succession (Zilhão et al., 2010, 2012). Archaeological findings comprise abundant lithic artefacts, hearth features and a perforated Pecten maximus shell bearing residues of pigment (Zilhão et al., 2010). Radiocarbon dating on wood charcoal from Cueva Antón using the ABOx-SC pre-treatment protocol (Acid-BaseOxidation-Stepped Combustion; Brock et al., 2010) dates 
unit II-b in the upper part of the archaeological succession (sub-complex AS1, see Fig. 2) to $32890 \pm 200$ BP (OxA-21244, 38440-36810 cal BP; Zilhão et al., 2010, Angelucci et al., 2013 and Wood et al., 2013). Further radiocarbon dates are available for units I-k of AS1 $(31070 \pm 170$ BP, OxA-20882) and II-h/i of AS2 $(39650 \pm 550$ BP, OxA-18672), but are considered unreliable due to the applied ABA (Acid-Base-Acid) pretreatment method that is shown to be less reliable in removing contaminants from charcoal (Jöris and Street 2008; Higham et al., 2009; Higham 2011; Maroto et al., 2012 and Wood et al., 2013).

This study focuses on the application of luminescence dating to the fluvial sediments of the middle to lower parts of the archaeological succession (AS2 to AS5) at Cueva Antón. Optically stimulated luminescence (OSL) provides the tools to not only cross-check the existing chronological framework, but also to provide first chronometric age estimates for the archaeological succession where radiocarbon dating failed due to insufficient yields of the charcoal samples (Zilhão et al., 2010). Moreover, the fluvial nature of the sediments (Angelucci et al., 2013) as well as the protected depositional environment in the rock shelter facilitates a challenging test bed to investigate the potential of various luminescence dating techniques. Since the advent of OSL dating (Huntley et al., 1985) there has been substantial progress both in instrumentation (cf. Bøtter-Jensen, 1997; Duller et al., 1999; Bøtter-Jensen et al., 1999, 2000, 2003, 2010; Thomsen et al., 2008a and Lapp et al., 2012) and in methodological aspects; for the latter most notably by the introduction of the single-aliquot regenerative-dose protocol (Murray and Wintle, 2000, 2003 and Wintle and Murray, 2006). One of the major challenges in luminescence dating with respect to fluvial sediments is the question of whether the luminescence signal was completely or only partially reset (also termed "bleached") during transport prior to deposition (Wallinga, 2002; Jain et al., 2004 and Rittenour, 2008). The use of increasingly smaller sub-samples ("aliquots") (Olley et al., 1998 and Duller, 2008) and single grain measurements (Duller et al., 1999 and Bøtter-Jensen et al., 2000) greatly improved the reliability of differentiating fully from partially bleached grains. Single grain dating has also been proved to be valuable for sediments in archaeological contexts, e.g. to identify the mixing of sediments due to human activity (Jacobs and Roberts, 2007). Likewise, substantial progress has been achieved in infrared stimulated luminescence (IRSL) dating of feldspar, which was long subordinate because of anomalous fading (Spooner, 1992, 1994), i.e. the loss of signal over time due to quantum mechanical tunnelling (Poolton et al., 2002). Besides methods for correcting anomalous fading (Huntley and Lamothe, 2001; Auclair et al., 2003 and Kars et al., 2008) the development of elevated temperature post-IR IRSL (pIRIR) dating protocols (Buylaert et al., 2009, 2012 and Thiel et al., 2011), which measure non-fading feldspar signals, initiated a series of studies to test their potential in various contexts (e.g. Kars et al., 2012; Lowick et al., 2012; Roberts, 2012 and Vasiliniuc et al., 2012).

Considering all this, there is now a wide variety of luminescence dating techniques available, each with their own assets and drawbacks. The present study applies and compares OSL dating on multiple and single grains of quartz. Additional post-IR IRSL dating on K-rich feldspars are carried out to shed further light on the bleaching history of the sediments. The analysis of various luminescence characteristics through a series of laboratory experiments and cross-validation by comparison of the performance of the dating techniques used was carried out in order to ascertain the most appropriate method for establishing a reliable chronostratigraphy for the archaeological record at Cueva Antón.

\section{STUDY SITE AND SAMPLES}

The Cueva Antón rock shelter $\left(38^{\circ} 3^{\prime} 51.84^{\prime \prime N}\right.$, $1^{\circ} 29^{\prime} 47.20^{\prime \prime} \mathrm{W}$ ), located in the province of Murcia (Southeast Spain), approximately $3 \mathrm{~km}$ north of the town of Mula and directly adjoining the River Mula, is one of several Middle Palaeolithic sites in the Murcia region (Zilhão and Villaverde, 2008). Situated in the vicinity of the Betic Cordillera to the north and the Mula-Pliego Basin to the south the rock shelter itself is located in the Mula valley at an altitude of $356 \mathrm{~m}$ above sea level. The local geology of Cueva Antón is mainly conditioned by the Paleocene to Miocene rocks that form the local Mula unit, with lower Miocene marls and marly limestones, which outcrop along several thrust faults, dominating (Fig. 1). The rock shelter itself is located at the base of a 25-30 m high escarpment of mainly middle-to-upper Eocene limestones comprising calcareous breccias and conglomerates, calcarenites as well as micritic and nummulitic limestones (Angelucci et al., 2013).

The stratigraphic layout of the succession in Cueva Antón can be divided in four main complexes (from top to bottom): i) DD (Dam Deposits), made of fine, mostly silty beds that accumulated over the last decades (caused by occasional floodings of the rock shelter due to the construction of the La Cierva Dam started in 1929), ii) TL (Transitional Layers), formed of disturbed layers of uncertain age in intermediate position between DD deposits and underlying Pleistocene sediments (in part, backdirt from the 1991 trench), iii) AS (Archaeological Succession), formed of a number of Upper Pleistocene superposed alluvial sequences featuring distinct sedimentary facies, lateral variations, and including intercalations of slope material (particularly near the back wall), and iv) FP (Fine Palustrine), a weakly bedded, fine, organic-rich sediment forming the base of the exposed succession (Zilhão et al., 2010 and Angelucci et al., 2013).

It is the AS complex which is of particular geoarchaeological interest and is best described as a well-preserved alluvial sequence. A continuous accumulation of alluvial 

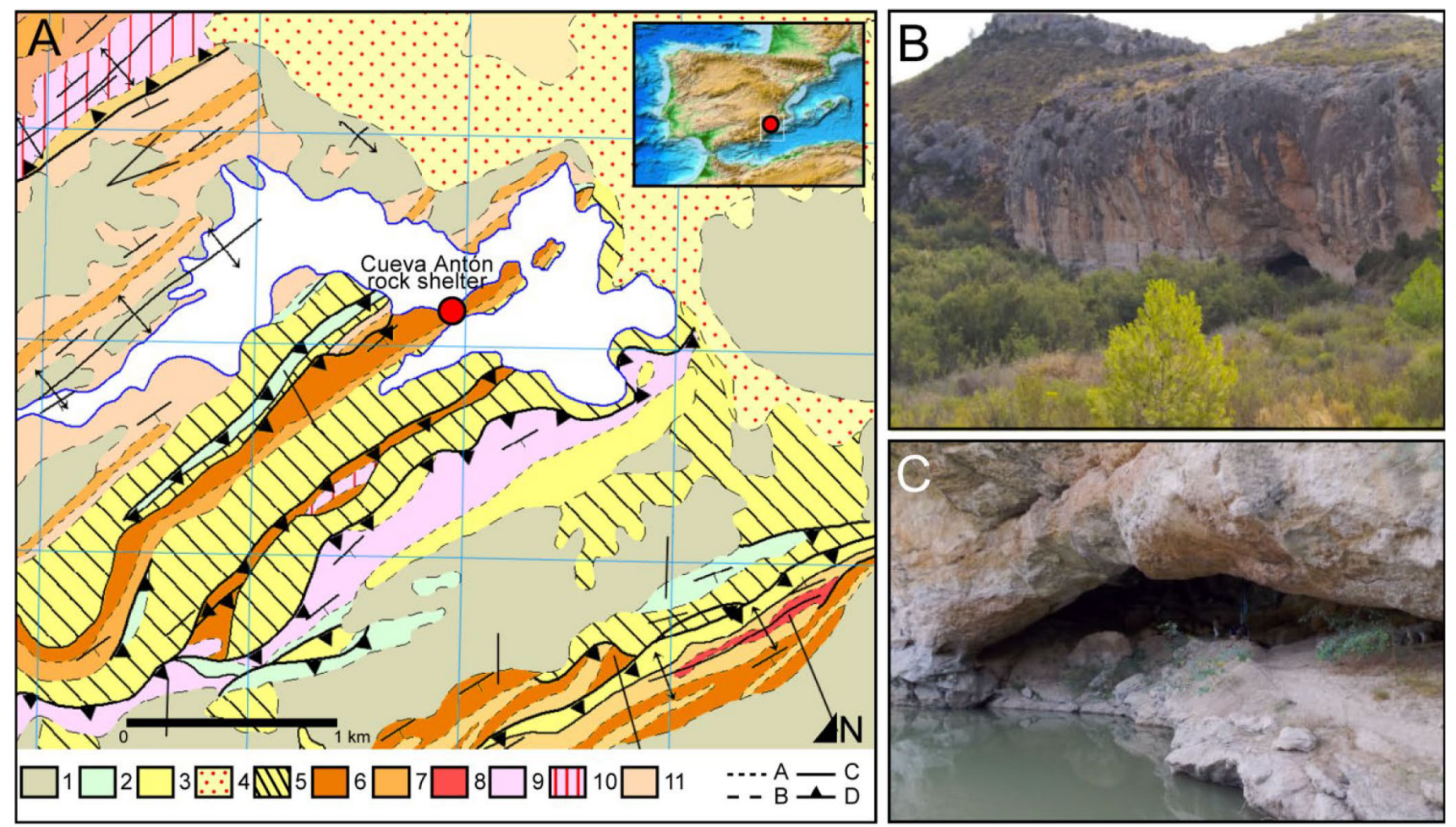

Fig. 1. Geological setting and photographs of the Cueva Antón rock shelter. A) Geological context of the Cueva Antón rock shelter in the geological map, scale 1:50 000 (IGME, 1972). Legend: A: Concordant contact; B: Discordant contact; C: Fault; D: Thrust; 1, undifferentiated, 2, limestones (Toarcian-Oxfordian, Tithonian), 3, polygenetic conglomerates, arenites and marls (Oligocene), 4, arenites, limestones and conglomerates (Tortonian), 5, marls and marly limestones (Lower Miocene), 6, marls with intercalations of nummulitic limestones (Lutetian), 7, limestones with Discocyclina (foraminifera) (Priabonian), 8, limestone conglomerates and marls (Paleocene-Lower Eocene), 9, nummulitic limestones (Lutetian), 10, limestones and marls (Ypresian-Lutetian), 11, marls with intercalations of nummulitic limestones (Priabonian). B) and C) photos of the Cueva Antón rock shelter.

beds with high sedimentation rates, the protective effect of the rock shelter and the incision of the River Mula preserved the sedimentary facies and archaeological elements from active surface dynamics, limited postdepositional dynamics and soil formation processes and spared the deposit from the subsequent action of fluvial dynamics (Angelucci et al., 2013). Based on sedimentary and stratigraphic criteria the AS complex can further be subdivided into five sub-complexes (further comprising 48 different units). For a detailed synopsis of the stratigraphic complexes the reader is referred to Angelucci et al. (2013).

While AS1 could successfully be dated by the radiocarbon method, no radiometric ages are available for the sub-complexes AS2 to AS5. Attempts at radiocarbon dating the base of the succession have failed so far due to insufficient yields of the charcoal samples (Zilhão et al., 2010). In order to provide first radiometric age estimates a total of nine samples were taken from the archaeological succession for luminescence dating by pushing opaque stainless steel tubes into various layers of two profiles (Fig. 2). The tubes were closed with opaque plastic caps, thus preventing an early reset of the luminescence signal. The first set of samples was taken during excavations in 2010 and a second during excavations in 2012. To determine the apparent residual dose in feldspar an additional modern-analogue sample (CA-7) was taken from a sub-recent fluvial terrace directly adjacent to the cave entrance of Cueva Antón.

\section{EXPERIMENTAL DETAILS}

\section{Sample preparation}

All sample preparation procedures were conducted under subdued red illumination, following routine procedures (Wintle, 1997). Chemical treatment of the bulk samples involved hydrochloric acid ( $\mathrm{HCl} \mathrm{10 \% ),} \mathrm{hydrogen}$ peroxide $\left(\mathrm{H}_{2} \mathrm{O}_{2} \quad 10 \%\right)$ and sodium oxalate $\left(\mathrm{Na}_{2} \mathrm{C}_{2} \mathrm{O}_{4}\right)$. During this procedure any carbonates were dissolved, organic matter oxidised and the clay fraction dispersed. Coarse grained quartz and K-rich feldspar were separated using sodium polytungstate with densities of $2.58 \mathrm{~g} \mathrm{~cm}^{-3}$, $2.62 \mathrm{~g} \mathrm{~cm}^{-3}$ and $2.68 \mathrm{~g} \mathrm{~cm}^{-3}$. The enriched quartz fraction was further etched in hydrofluoric acid (HF 40\%, $40 \mathrm{~min}$ ) to remove any remaining feldspars and the outer layer of the quartz grains that received an alpha dose from the environment. Precipitated fluorides were removed by $\mathrm{HCl}$ $(10 \%)$ wash for one hour. Depending on the amount of remaining sample material purified quartz and feldspars were sieved to $100-150 \mu \mathrm{m}$ or $100-200 \mu \mathrm{m}$. For single 


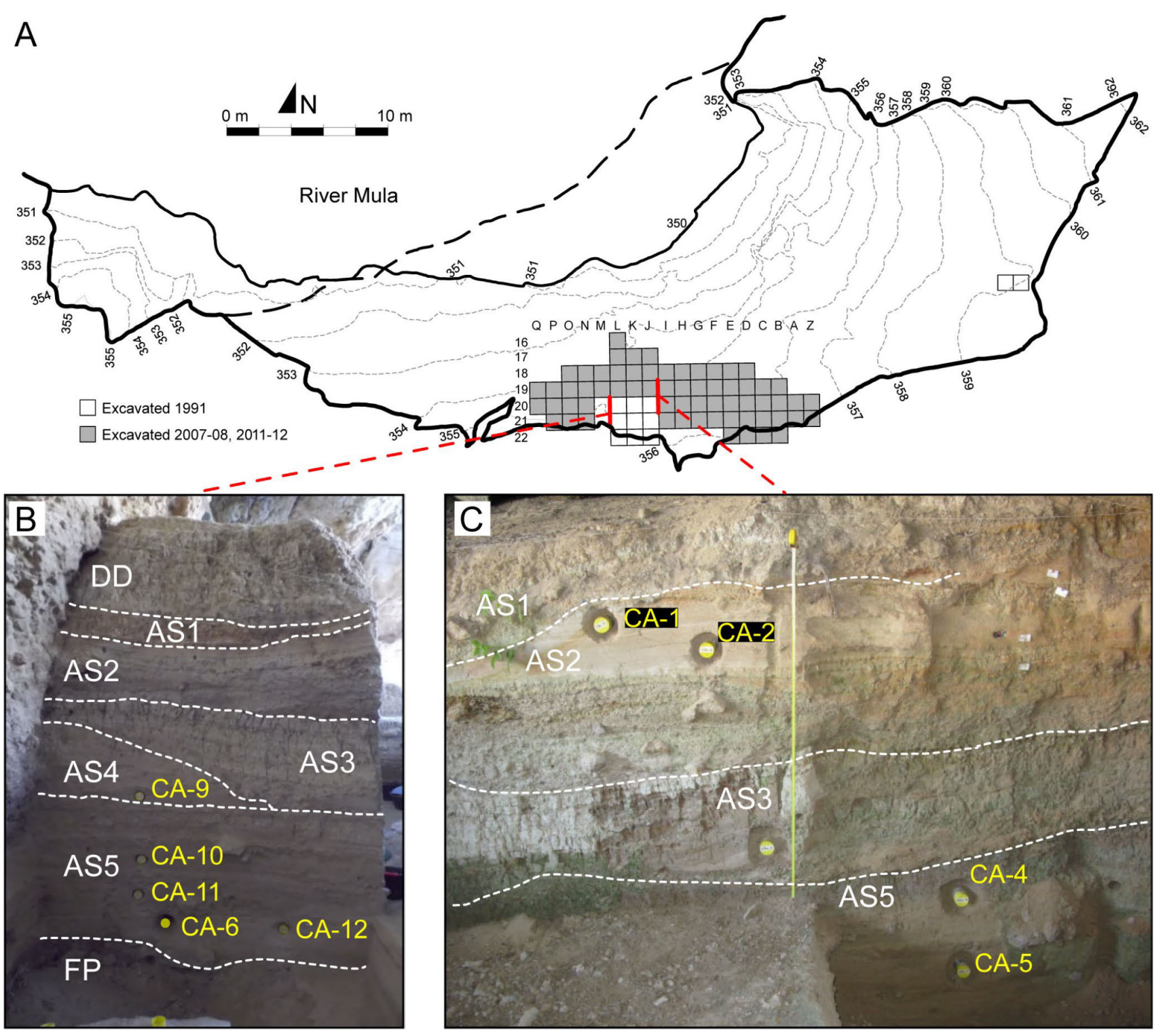

Fig. 2. Luminescence sampling at Cueva Antón. A) Site plan and excavated areas of the Cueva Antón rock shelter. Elevations are given in metres above sea level (modified from Angelucci et al., 2013). B) The W wall of trench $L$ (square $L 20$ to $L 21$ ). Samples and excavation units: CA-9, II- $\varnothing ;$; CA10, III-e/h; CA-11, III-k/l; CA-12, III-m; CA-6, III-m. C) The E wall of trench J (square J19 to J20). Samples and excavation units: CA-1, II-e; CA-2, II-e; $C A-4$, II-y; CA-5, III-f. Dashed lines indicate stratigraphic complexes and sub-complexes. AS = Archaeological Succession, DD = Dam Deposits, $F P=$ Fine Palustrine.

grain measurements of quartz the $200-250 \mu \mathrm{m}$ grain size fraction was extracted. Additionally, for sample CA-9 the 40-63 $\mu \mathrm{m}$ quartz grain size fraction was prepared, applying the same chemical treatment as above. Mineral separation was achieved by etching the bulk sample in hexafluorosilicic acid $(34 \%, 14$ d). Precipitated fluorides were removed by $\mathrm{HCl} 10 \%$ wash.

\section{Instrumentation}

Luminescence measurements were conducted on Risø TL/OSL-DA-15/20 readers equipped with ${ }^{90} \mathrm{Sr} /{ }^{90} \mathrm{Y}$ beta sources for irradiation and delivering dose rates between
$0.08 \mathrm{~Gy} \mathrm{~s}^{-1}$ and $0.15 \mathrm{~Gy} \mathrm{~s}^{-1}$. Optical stimulation of quartz multiple grain samples was performed at $80-90 \%$ power using blue diodes $(470 \pm 30 \mathrm{~nm})$ for $40 \mathrm{~s}$ (Bøtter-Jensen et al., 1999). Single grains of quartz were stimulated for $2 \mathrm{~s}$ with a green $\mathrm{Nd}: \mathrm{YVO}_{4}$ diode-pumped laser $(532 \mathrm{~nm})$ delivering a power density of $\sim 50 \mathrm{~W} \mathrm{~cm}{ }^{-2}$ (Bøtter-Jensen et al., 2000). Feldspar samples were measured at $90 \%$ power using infrared diodes $(880 \pm 80 \mathrm{~nm})$ for $200 \mathrm{~s}$. Luminescence signals were detected with an EMI 9235 photomultiplier through a $7.5 \mathrm{~mm}$ thick Hoya U340 (quartz) and $410 \mathrm{~nm}$ interference filter (feldspar). 
The beta sources of three individual Risø TL/OSL reader with single grain attachments were calibrated using the BAG478 calibration quartz, which was thermally sensitised and homogeneously dosed to 8.03 Gy using ${ }^{60} \mathrm{Co} \gamma$-source. Following the approach of Ballarini et al. (2006) about 500 individual $D_{\mathrm{e}}$ values (in seconds) in average were obtained for each reader. The relative standard deviation of $D_{\mathrm{e}}$ values obtained for each single grain position remained $<20 \%$ in all cases. The spatial variability in the delivered dose rate was assessed by $3 \mathrm{D}$ plots (Fig. S1 in the Appendix). It is evident that the spatial distribution of delivered dose rate is very specific to individual beta sources (cf. Spooner and Allsop, 2000; Ballarini et al., 2006 and Lapp et al., 2012). While two beta sources have a near-uniform dose rate distribution, a clear trend in delivered dose was identified for one of the beta sources and reconfirmed a previous calibration of the same source by Lomax (2009). When applying individual dose rates to calculate single grain $D_{\mathrm{e}}$ estimates, the overdispersion (OD), calculated using the central age model (CAM, Galbraith et al., 1999), could be reduced by up to 6.5 percentage points (Table 1). However, even after correction of the non-uniform beta dose rate an OD of 8$12 \%$ remained, which is in the range or slightly larger than the values of $6.9 \%$ and $7.3 \%$ reported in Thomsen et al. (2005). Similar values of $11.4 \%$ and $12 \%$ for gamma dosed single grain distributions are also reported in Thomsen et al. (2007).

\section{Equivalent dose estimation}

Quartz OSL was measured using a standard quartz SAR protocol after Murray and Wintle $(2000,2003)$ employing preheat temperatures of either $200^{\circ} \mathrm{C}$ or $220^{\circ} \mathrm{C}$ for $10 \mathrm{~s}$ (see Section 4 - Luminescence characteristics). The cutheat temperature was always chosen to be $20^{\circ} \mathrm{C}$ lower than the preheat temperature. Values for $L_{\mathrm{x}}$ and $T_{\mathrm{x}}$ were derived from the initial $0.8 \mathrm{~s}$ of the OSL signal, minus a background estimated from the last $5.0 \mathrm{~s}$ of the stimulation curve. For single grain measurements the OSL signal was derived from the first $0.054 \mathrm{~s}$ of stimulation, minus a background of the last $0.4 \mathrm{~s}$. IRSL on feldspars was measured using the pIRIR 225 and pIRIR $_{290}$ protocols (Buylaert et al., 2009 and Thiel et al., 2011) employing preheat temperatures of $250^{\circ} \mathrm{C}$ and $320^{\circ} \mathrm{C}$ for $60 \mathrm{~s}$, respectively. For both protocols the pIRIR stimula- tion time was $200 \mathrm{~s}$, and after every SAR cycle the samples were IR-stimulated at $290^{\circ} \mathrm{C}\left(\mathrm{pIRIR}_{225}\right)$ and $325^{\circ} \mathrm{C}$ $\left(\mathrm{pIRIR}_{290}\right)$ for $100 \mathrm{~s}$ to minimise any build-up of charge giving rise to a recuperated signal. The pIRIR signals were derived from the first $2.4 \mathrm{~s}$ of the IR stimulation with a subtracted background of the last $40 \mathrm{~s}$. For single and multiple grains of quartz test doses of 20 Gy were applied, whereas a higher test dose of 40 Gy was used for all feldspar measurements. All dose response curves were fitted with a single saturating exponential function.

\section{Dosimetry}

Samples for dose rate determination were dried at $105^{\circ} \mathrm{C}$ for $24 \mathrm{~h}$ and finally homogenised with a mortar. The homogenised samples were filled in Marinelli beakers of different standardised geometries filled with either $830 \mathrm{~g}$ or $1459 \mathrm{~g}$ sample material. After storing the samples for at least four weeks to allow equilibrium reestablishment of ${ }^{226} \mathrm{Ra}$ and its daughter nuclides, the samples were measured for $20 \mathrm{~h}$ in a high-resolution gammaray spectrometer with a coaxial P-type high purity germanium (HPGe) detector. The uranium $\left({ }^{238} \mathrm{U}\right)$ and thorium $\left({ }^{232} \mathrm{Th}\right)$ contents were calculated by measuring the gamma rays of the corresponding daughter nuclides ${ }^{226} \mathrm{Ra},{ }^{214} \mathrm{~Pb},{ }^{214} \mathrm{Bi}$ and ${ }^{228} \mathrm{Ac},{ }^{212} \mathrm{~Pb},{ }^{208} \mathrm{Tl}$, respectively. For all samples the specific activity $\left(\mathrm{Bq} \mathrm{kg}{ }^{-1}\right)$ of these nuclides were compared to check for indications of a disequilibrium in the ${ }^{238} \mathrm{U}$ and ${ }^{232} \mathrm{Th}$ decay series. None of the samples showed aberrant behaviour, hence a secular equilibrium was assumed. The potassium content $\left({ }^{40} \mathrm{~K}\right)$ was determined by measuring the $1460 \mathrm{keV}$ gamma ray that is emitted during the electron capture decay to ${ }^{40} \mathrm{Ar}$. The nuclide activities of ${ }^{238} \mathrm{U},{ }^{232} \mathrm{Th}$ and ${ }^{40} \mathrm{~K}$ were converted to dose rates using the conversion factors given in Guérin et al. (2011). To account for the attenuation of $\beta$-particles in grains correction factors of Mejdahl (1979) were used.

The cosmic-ray dose rates were calculated according to Prescott and Hutton (1994), taking into consideration the altitude and geomagnetic latitude of the sampling site and the thickness, density and water content of the overlying sediments. For near surface samples (CA-1, CA-2) the cosmic-ray dose rate was modelled using a polynomial component fitted to data presented by Prescott and Hutton (1988). The attenuation of cosmic-rays in the

Table 1. Summary of beta dose rate assessment for three Risø TLOOSL readers with single grain attachments. Calibration of the beta sources was done using a calibration quartz that was thermally sensitised and homogeneously dosed to 8.03 Gy using a ${ }^{60} \mathrm{Co}$ gamma source. The overdispersion was calculated using the central age model (Galbraith et al., 1999). The variation in delivered beta dose rate was highest for Reader C (see also Fig. S1 in the Appendix).

\begin{tabular}{cccccccc}
\hline Reader & $\begin{array}{c}\text { Number of grains } \\
\text { accepted/measured }\end{array}$ & $\begin{array}{c}\text { Mean dose } \\
\text { rate } \\
\left(\mathrm{Gy} \mathrm{s}^{-1}\right)\end{array}$ & $\begin{array}{c}\text { Lowest individual } \\
\text { dose rate } \\
\left(\mathrm{Gy} \mathrm{s}^{-1}\right)\end{array}$ & $\begin{array}{c}\text { Highest individual } \\
\text { dose rate } \\
\left(\mathrm{Gy} \mathrm{s}^{-1}\right)\end{array}$ & $\begin{array}{c}\text { RSD } \\
(\%)\end{array}$ & $\begin{array}{c}\text { Overdispersion in } D_{\mathrm{e}} \\
\text { values } \\
\text { (mean dose rate) }\end{array}$ & $\begin{array}{c}\text { Overdispersion } \\
\text { in } D_{\mathrm{e}} \text { values } \\
\text { (individual dose rate) }\end{array}$ \\
\hline $\mathrm{B}$ & $635 / 1700$ & 0.088 & 0.066 & 0.107 & 9.2 & $12.4 \pm 0.2$ & $11.1 \pm 0.2$ \\
\hline $\mathrm{C}$ & $553 / 1700$ & 0.148 & 0.104 & 0.201 & 15.4 & $18.2 \pm 0.3$ & $11.7 \pm 0.2$ \\
\hline $\mathrm{F}$ & $415 / 2400$ & 0.081 & 0.072 & 0.097 & 6.3 & $9.1 \pm 0.2$ & $8.1 \pm 0.2$ \\
\hline
\end{tabular}


overlying rock was accounted for and a correction for the geometric shielding by the rockshelter was incorporated using the equations given by Dunne et al. (1999).

To account for the external alpha dose rate of the outer rim of the mineral grains alpha efficiencies (a-values) of $0.07 \pm 0.02$ and $0.035 \pm 0.003$ were used for feldspar and quartz, respectively (Preusser et al., 2005 and Lai et $a l ., 2008)$. In addition, for K-rich feldspar an internal beta dose rate due to an internal ${ }^{40} \mathrm{~K}$-content has to be considered for age calculation. As the internal K-content was not specifically measured, a potassium concentration of $12.5 \pm 0.5 \%$ (Huntley and Baril, 1997) was assumed. While indirect (Reimann et al., 2012a) and direct (Zhao and Li, 2005 and Smedley et al., 2012) determinations confirm a large variability of internal K-contents in feldspar, a mean potassium concentration of $12.5 \pm 0.5 \%$ for multiple grain measurements is still likely to be a valid estimate (Smedley et al., 2012).

Because water has a higher radiation absorption coefficient than air it is necessary to estimate the water content of the sample. Measured present day water contents varied from $1 \%$ to $19 \%$. However, these values were assumed to be not representative for the water content over the burial time. On the basis of soil texture and pore space, assuming predominantly cold and dry climate conditions during the Late Pleistocene (Fletcher and Sánchez Goñi, 2008 and Vegas et al., 2010) and taking into consideration the sheltering from direct precipitation, a long-term water content of $5 \pm 3 \%$ was estimated instead and used to correct the alpha, beta and gamma dose rates with correction factors given in Aitken (1985). Dosimetry data are summarised in Table 2.

\section{RESULTS}

\section{Luminescence characteristics}

Quartz and feldspar from Cueva Antón showed bright OSL and IRSL signals, respectively (Fig. 3). Multiple grain aliquots were rejected when the recycling ratio exceeded 1.1 or was less than 0.9 (Murray and Wintle, 2000). Single grains of quartz were discarded when the recycling ratio exceeded 1.2 or was less than 0.8 (cf. Jacobs et al., 2003). The error on the recycling ratio was not considered. Multiple grain aliquots of quartz and feldspar and single quartz grains were rejected when the recuperation ratio, i.e. the quotient of the $L_{\mathrm{x}} / T_{\mathrm{x}}$ ratio of the zero dose and the $L_{\mathrm{n}} / T_{\mathrm{n}}$ ratio of the natural dose, exceeded 5\% (Murray and Wintle, 2000). Furthermore, only aliquots and single grains of quartz having an OSL IR depletion ratio (Duller, 2003) between 1.1 and 0.9 were accepted. Further aliquots and single quartz grains were rejected if the net OSL signal was not at least three standard deviations above background, the test doses error was $>5 \%$, or when no meaningful curve-fit of the doseresponse curve could be calculated.

To assess the variability in the saturation dose $D_{0}$ of quartz from Cueva Antón a single saturating exponential was fitted to all aliquots and single grains that passed the rejection criteria. Mean $D_{0}$ values varied between 63 and 67 Gy when measured on multiple grain aliquots. However, for a specific sample $D_{0}$ values varied significantly from aliquot to aliquot with standard deviations ranging from 7 Gy ( $8 \mathrm{~mm}$ aliquots) to $22 \mathrm{~Gy}$ ( $1 \mathrm{~mm}$ aliquots). The variability in $D_{0}$ values determined on single grains of quartz on samples CA-1 and CA-5 is even larger with mean saturation doses of $63 \pm 28$ Gy and $60 \pm 27 \mathrm{~Gy}$, respectively.

Table 2. Dosimetry data for quartz and feldspar samples from Cueva Antón. Nuclide contents of $U$, Th and ${ }^{40} \mathrm{~K}$ were derived from measurements using a high-resolution gamma-ray spectrometer with a coaxial P-type high purity germanium (HPGe) detector. Measured water contents were assumed to be not representative for the water content over the burial time and a long-term water content of $5 \pm 3 \%$ was estimated instead. The water content is expressed as mass of dry sediment. $Q=$ quartz, $F S=$ feldspar, $W C M=$ water content measured, $A W C=$ assumed water content.

\begin{tabular}{|c|c|c|c|c|c|c|c|c|c|c|}
\hline Sample & $\begin{array}{l}\text { Depth } \\
\text { (m) }\end{array}$ & Mineral & $\begin{array}{l}\text { Grain size } \\
\qquad(\mu \mathrm{m})\end{array}$ & $\begin{array}{l}\text { Uranium } \\
\text { (ppm) }\end{array}$ & $\begin{array}{l}\text { Thorium } \\
\text { (ppm) }\end{array}$ & $\begin{array}{l}\text { Potassium } \\
(\%)\end{array}$ & $\begin{array}{c}\text { WCM } \\
(\%)\end{array}$ & $\begin{array}{c}\text { AWC } \\
(\%)\end{array}$ & $\begin{array}{l}\text { Cosmic dose } \\
\text { rate }\left(G y k^{-1}\right)\end{array}$ & $\begin{array}{c}\text { Total dose } \\
\text { rate } \mathrm{D}_{0} \\
\left(\mathrm{~Gy} \mathrm{ka}^{-1}\right)\end{array}$ \\
\hline CA-1 & 0.27 & $Q$ & $\begin{array}{l}100-150 \\
200-250\end{array}$ & $1.15 \pm 0.06$ & $2.02 \pm 0.13$ & $0.40 \pm 0.02$ & 18.9 & $5 \pm 3$ & 0.103 & $0.87 \pm 0.10$ \\
\hline CA-1 & 0.27 & FS & $100-150$ & $1.15 \pm 0.06$ & $2.02 \pm 0.13$ & $0.40 \pm 0.02$ & 18.9 & $5 \pm 3$ & 0.103 & $1.35 \pm 0.14$ \\
\hline CA-2 & 0.38 & $Q$ & $100-150$ & $1.18 \pm 0.08$ & $2.49 \pm 0.17$ & $0.46 \pm 0.03$ & 4.1 & $5 \pm 3$ & 0.100 & $0.97 \pm 0.12$ \\
\hline CA-4 & 1.54 & $Q$ & $100-200$ & $1.38 \pm 0.07$ & $2.88 \pm 0.17$ & $0.54 \pm 0.02$ & 16.7 & $5 \pm 3$ & 0.073 & $1.08 \pm 0.13$ \\
\hline CA-5 & 1.88 & $Q$ & $\begin{array}{l}100-200 \\
200-250\end{array}$ & $1.01 \pm 0.06$ & $1.50 \pm 0.10$ & $0.33 \pm 0.01$ & 8.4 & $5 \pm 3$ & 0.066 & $0.70 \pm 0.09$ \\
\hline CA-5 & 1.88 & $\mathrm{FS}$ & $100-150$ & $1.01 \pm 0.06$ & $1.50 \pm 0.10$ & $0.33 \pm 0.01$ & 8.4 & $5 \pm 3$ & 0.066 & $1.18 \pm 0.16$ \\
\hline$\overline{\mathrm{CA}-6}$ & 2.78 & $Q$ & $100-150$ & $1.15 \pm 0.08$ & $2.45 \pm 0.17$ & $0.42 \pm 0.02$ & 12.3 & $5 \pm 3$ & 0.048 & $0.86 \pm 0.12$ \\
\hline CA-9 & 2.26 & $Q$ & $100-150$ & $1.02 \pm 0.06$ & $1.84 \pm 0.11$ & $0.27 \pm 0.01$ & 1.5 & $5 \pm 3$ & 0.058 & $0.67 \pm 0.08$ \\
\hline CA-10 & 2.51 & $Q$ & $\begin{array}{c}40-63 \\
100-150\end{array}$ & $0.93 \pm 0.07$ & $1.41 \pm 0.11$ & $0.27 \pm 0.02$ & 1.9 & $5 \pm 3$ & 0.053 & $0.65 \pm 0.08$ \\
\hline CA-11 & 2.66 & $Q$ & $100-150$ & $1.01 \pm 0.07$ & $1.56 \pm 0.12$ & $0.30 \pm 0.02$ & 2.3 & $5 \pm 3$ & 0.050 & $0.66 \pm 0.08$ \\
\hline CA-12 & 2.78 & $Q$ & $100-150$ & $1.22 \pm 0.09$ & $2.32 \pm 0.18$ & $0.39 \pm 0.02$ & 3.3 & $5 \pm 3$ & 0.048 & $0.85 \pm 0.10$ \\
\hline
\end{tabular}



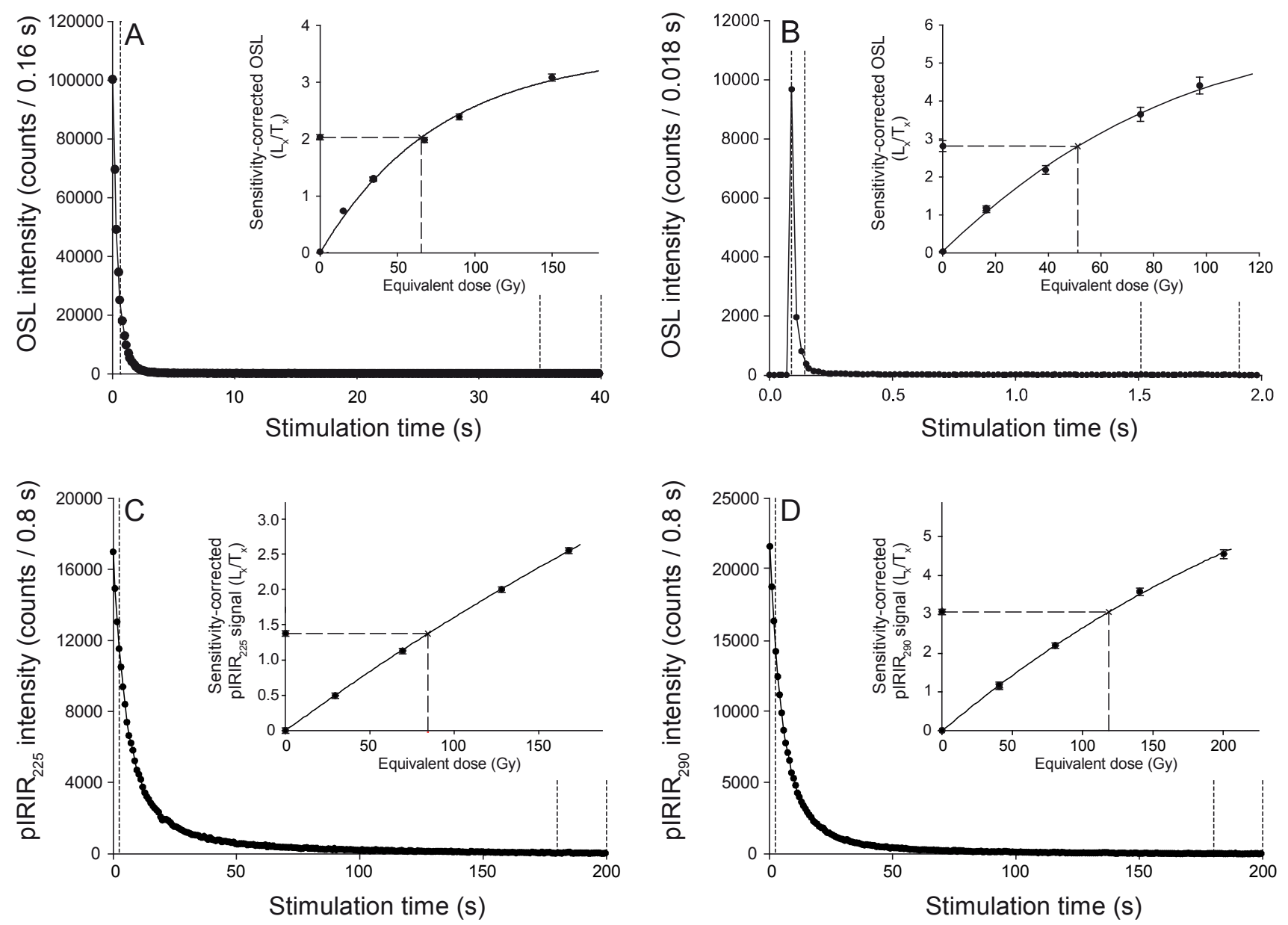

Fig. 3. Representative luminescence decay curves and corresponding dose response curves for quartz and feldspar samples from Cueva Antón. A) Quartz OSL intensity of a multiple grain aliquot $(1 \mathrm{~mm})$ from sample CA-6 during stimulation with blue diodes. B) OSL intensity of a single quartz grain from sample CA-1 during stimulation with a green laser. C) and D) show the pIRIR decay curves during elevated stimulation temperature readouts at $225^{\circ} \mathrm{C}$ and $290^{\circ} \mathrm{C}$, respectively. For quartz multiple grain measurements the signal of the initial $0.8 \mathrm{~s}$ were used minus a background of the last $5 \mathrm{~s}$ of stimulation. For single grain measurements the OSL signal was derived from the first $0.054 \mathrm{~s}$ of stimulation minus a background of the last $0.4 \mathrm{~s}$. Both pIRIR signals were derived from the first $2.4 \mathrm{~s}$ of the IR stimulation with a subtracted background of the last $40 \mathrm{~s}$. The insets show the sensitivity corrected dose response curves. Vertical dashed lines indicate the initial integral used to obtain the luminescence signal and the time interval used for background subtraction.

The signal composition of quartz was checked by linearly modulated (LM-)OSL measurements conducted on five $8 \mathrm{~mm}$ aliquots for samples CA-1 and CA-6, respectively (Fig. S2 in the Appendix). Deconvolution of the LM-OSL curves was done using the fit_LMCurve() function of the R package 'Luminescence' (Kreutzer et al., 2012). Analysis of the deconvolved LM-OSL curves revealed the presence of four signal components. Mean values for photoionisation cross-section of components were (from component 1 to component 4): $2.73 \pm 0.12 \times 10^{-17} \mathrm{~cm}^{2}, \quad 2.63 \pm 0.21 \times 10^{-18} \mathrm{~cm}^{2}$, $2.37 \pm 0.13 \times 10^{-19} \mathrm{~cm}^{2}$, and $2.32 \pm 0.4 \times 10^{-20} \mathrm{~cm}^{2}$. Component $1 \mathrm{can}$ be associated with the fast component. For these samples the fast component is dominant and makes up $80-85 \%$ of the net OSL signal.
A preheat plateau test was done on $8 \mathrm{~mm}$ aliquots from sample CA-1 (Fig. 4). The $D_{\mathrm{e}}$ was measured in groups of five for different preheat temperatures in steps of $20^{\circ} \mathrm{C}$ ranging from $180^{\circ} \mathrm{C}$ to $300^{\circ} \mathrm{C}$ (held for $10 \mathrm{~s}$ ). The cutheat temperature was always chosen to be $20^{\circ} \mathrm{C}$ lower than the preheat temperature. Fig. 4 indicates a preheat plateau between $200-240^{\circ} \mathrm{C}$. Additionally, a set of combined dose recovery preheat plateau tests were carried out on small aliquots $(1$ and $2 \mathrm{~mm})$ of samples CA-1, CA-2 and CA-9 (Fig. 5). The naturally trapped charge was removed by blue stimulation for $150 \mathrm{~s}$ at room temperature. The samples were then given a laboratory dose of $60 \mathrm{~Gy}$. For all samples the dose recovery ratios were in agreement within $10 \%$ of unity for preheat temperatures from $180^{\circ} \mathrm{C}$ to $280^{\circ} \mathrm{C}$. 
Based on these tests a preheat temperature in the range of $200-240^{\circ} \mathrm{C}$ was considered to be appropriate for the samples under study. For all subsequent quartz OSL measurements a preheat/cutheat combination of either $200 / 180^{\circ} \mathrm{C}$ or $220 / 200^{\circ} \mathrm{C}$ was used. The same thermal treatment was applied in the SAR protocol for single grain measurements.

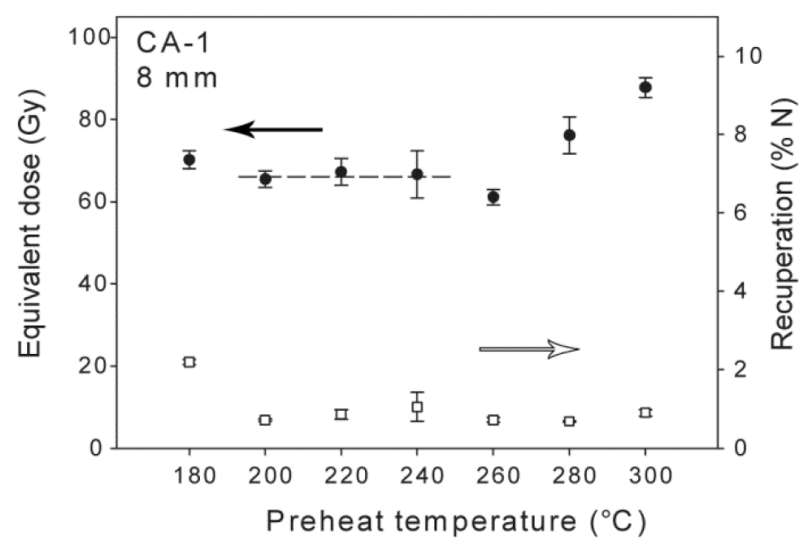

Fig. 4. Dependency of $D_{e}$ on preheat temperature deduced from a preheat plateau test for sample CA-1. Filled circles indicate the mean $D_{e}$ of five aliquots measured for each preheat temperature. The error bars are the standard error of dose estimates obtained for each temperature. Open squares are the recuperation rate, i.e. the quotient of the $L_{x} / T_{x}$ ratio of the zero dose and the $L_{n} / T_{n}$ ratio of the natural dose, expressed in percent. The preheat plateau test was conducted on large $8 \mathrm{~mm}$ aliquots and shows a well-defined preheat plateau ranging from $200^{\circ} \mathrm{C}$ to $240^{\circ} \mathrm{C}$. The mean recuperation rate always remained below $5 \%$ of the natural signal.
To check the applicability of all applied protocols for quartz and feldspar a series of dose recovery tests were conducted. Details on the dose recovery tests and their results are given in Table 3. In all cases the administered dose could be recovered within $10 \%$ of unity. For quartz the mean dose recovery ratio was $0.99 \pm 0.04$ and $1.04 \pm 0.06$ for feldspar. The dose recovery tests on feldspar indicate a better reproducibility of the pIRIR $_{225}$ signal over the pIRIR $_{290}$ signal.

Table 3. Summary of dose recovery tests. Small aliquots of quartz were optically bleached for $150 \mathrm{~s}$ at room temperature with blue diodes. The natural OSL signal of single quartz grains was removed by a repeated green laser stimulation for $4 s$ (at $25 \%$ laser power) at room temperature with an intermediate pause of $10000 \mathrm{~s}$ (cf. Duller, 2012). Cross-checking the OSL decay curves of both stimulations revealed that the natural signal of all grains was fully reset prior to irradiation. Feldspar aliquots were bleached for $1 \mathrm{~h}$ in a Hönle SOL2 solar simulator (a) and in the Risø TL/OSL reader by a repeated 200 s IR stimulation with an intermediate pause of $1000 \mathrm{~s}(\mathrm{~b})$. For the aliquots bleached in the solar simulator residual doses of $4.2 \mathrm{~Gy}$ (pIRIR225) and $12.6 \mathrm{~Gy}$ $\left(p / R I R_{290}\right)$ were subtracted, which were measured on separate aliquots after the same bleaching conditions (see Fig. S5 in the Appendix). In all cases the applied laboratory doses could be recovered within $10 \%$ of unity. $S G=$ single grain.

\begin{tabular}{|c|c|c|c|c|c|c|c|}
\hline 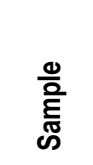 & $\begin{array}{l}\overline{\frac{\pi}{2}} \\
\stackrel{\stackrel{5}{\Sigma}}{\Sigma}\end{array}$ & $\begin{array}{l}\overline{0} \\
\stackrel{0}{0} \\
\text { o. }\end{array}$ & $\begin{array}{l}\frac{\mathbb{N}}{\omega} \\
\stackrel{\frac{5}{N}}{\frac{E}{5}}\end{array}$ & 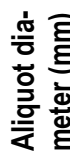 & 交 & $=$ & 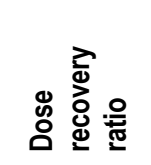 \\
\hline A- & $\bar{Q}$ & $\mathrm{R}$ & -150 & 2 & 60 & 2 & 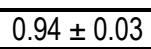 \\
\hline $\mathrm{CA}-1$ & $Q$ & SAR & -250 & $S G$ & 50 & 27 & \\
\hline CA-1 & FS & $\mathrm{IRIR}_{225}$ & $0-150$ & 1 & 87 & 3 & $0.96 \pm 0.07^{a}$ \\
\hline CA-1 & FS & $\mathrm{plR} \mathrm{R}_{225}$ & $0-150$ & 1 & 87 & 3 & $0.99 \pm 0.01^{b}$ \\
\hline 41 & FS & & & 1 & 117 & & $1.09 \pm$ \\
\hline CA-1 & FS & & 11 & 1 & 11 & & \\
\hline CA-9 & $Q$ & SAR & $100-150$ & 1 & 60 & 17 & $1.04 \pm 0.02$ \\
\hline-10 & Q & $\mathrm{AR}$ & $40-63$ & 1 & 60 & 20 & .01 \\
\hline
\end{tabular}
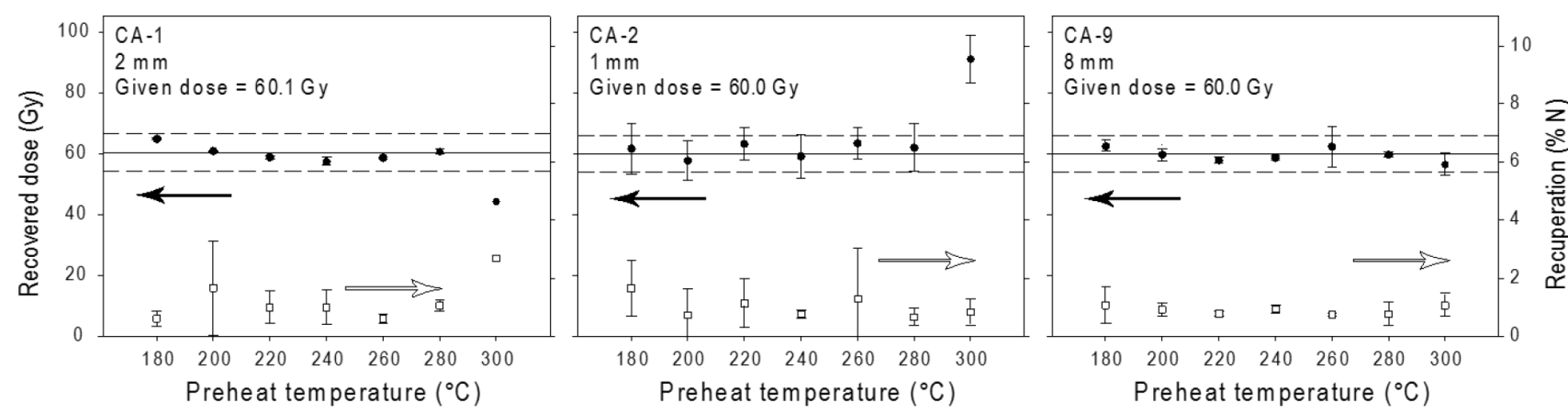

Fig. 5. Dependency of $D_{e}$ on preheat temperature deduced from "dose recovery preheat plateau" tests for samples $C A-1, C A-2$ and $C A-9$. Fillea circles indicate the mean $D_{e}$ of three or four aliquots measured for each preheat temperature. The error bars are the standard error of dose estimates obtained for each temperature. Open squares are the mean recuperation rates. Solid line represents the given laboratory dose; dashed lines represent $10 \%$ uncertainty. For all three samples the laboratory dose of $\sim 60$ Gy could be recovered within $10 \%$ of unity for preheat temperatures from $180^{\circ} \mathrm{C}$ to $280^{\circ} \mathrm{C}$. In all cases the mean recuperation rate remained below $5 \%$ of the natural signal. 


\section{Estimating the amount of grains on a sample disc}

Multiple grain $D_{\mathrm{e}}$ estimation techniques are known to be prone to averaging effects (e.g. Duller, 2008 and Arnold and Roberts, 2009) and there is an increasing number of single grain studies where aberrant grain behaviour was found to be the cause for $D_{\mathrm{e}}$ over- and underestimations on the multiple grain scale (e.g. Arnold et al., 2012; Stone and Bailey, 2012 and Demuro et al., 2008, 2013). However, when dealing with averaging effects in multiple grain measurements there is the obvious question on how many grains are actually present on an aliquot that potentially contribute to the measured OSL signal. Here, we adopted the approach of Heer et al. (2012), who presented empirical data on this issue, and estimated the number of grains $n$ on an aliquot by assuming a twodimensional 'Packing Equal Circles in a Circle' (PECC) problem (cf. Huang and Ye, 2011) and using the following equation

$n=\frac{\pi r_{c}^{2}}{\pi r_{g}^{2}} d$

where $r_{\mathrm{c}}$ is the radius of the aliquot $(\mathrm{mm}), r_{\mathrm{g}}$ is the mean radius of the grain size fraction $(\mathrm{mm})$ and $d$ is the packing density (value between 0 and 1). Instead of assuming $d=\pi / \sqrt{12} \approx 0.907$ (e.g. Rhodes, 2007 and Heer et al., 2012), a value that can only be achieved in a densest circle packing on an infinite plane (Chang and Wang 2010), packing density values were taken from Specht (2012). Here, packing density values vary between 0.656 and 0.875 for $n$ up to 1500 (omitting values for $n=1$ and 2). In addition, multiple grain aliquots in 1,2 and $8 \mathrm{~mm}$ diameter were prepared as described in Heer et al. (2012) and photographed with a digital Keyence VHX-2000 microscope in order to count the number of grains on the disc. The results are shown in Table 4.

Table 4. Results of counting grains on single aliquot discs. Values for maximum packing density $d$ were taken from Specht (2012). A mean packing density of 0.68 was calculated, which is significantly lower than the commonly assumed packing density of $\sim 0.907$, a value that can only be achieved in the densest hexagonal circle packing on an infinite plane (Chang and Wang, 2010).

\begin{tabular}{|c|c|c|c|c|c|c|c|}
\hline 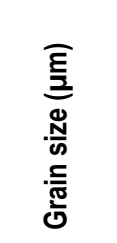 & 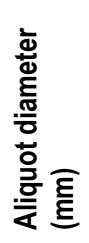 & 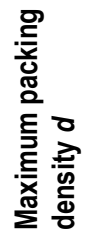 & 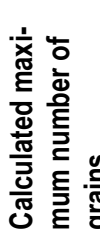 & 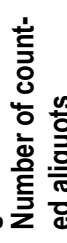 & 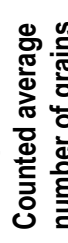 & 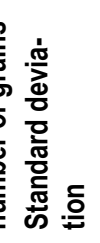 & $\begin{array}{l}0 \\
\frac{0}{0} \\
\frac{1}{0} \\
\frac{0}{0} \\
\frac{0}{0} \\
\frac{D}{0} \\
\frac{0}{0} \\
0\end{array}$ \\
\hline $40-63$ & 1 & 0.85 & 320 & 3 & 387 & 10 & 1.03 \\
\hline $40-63$ & 2 & 0.86 & 1304 & 3 & 807 & 62 & 0.54 \\
\hline $100-150$ & 1 & 0.78 & 55 & 6 & 34 & 14 & 0.53 \\
\hline $100-150$ & 2 & 0.83 & 221 & 6 & 180 & 36 & 0.70 \\
\hline $100-200$ & 1 & 0.78 & 35 & 1 & 31 & - & 0.70 \\
\hline $100-200$ & 2 & 0.82 & 146 & 1 & 101 & - & 0.57 \\
\hline
\end{tabular}

It is evident that there is a substantial discrepancy between the theoretical and actual number of grains on an aliquot, even when assuming maximum packing densities in a PECC problem. In addition to the possible reasons given by Heer et al. (2012) it has to be considered that preparing the aliquot by sprinkling the grains on the disc is a highly random process. Thus, the probability of arranging the grains in the densest possible configuration on the disc can be considered zero. One exception to this observation is the calculated packing density of 40 $64 \mu \mathrm{m}$ grains on $1 \mathrm{~mm}$ aliquots. Possible reasons for a packing density $d \geq 1$ are: a) the desired aliquot diameter is in reality larger than $1 \mathrm{~mm}$ (e.g. due to imprecise disc preparation), b) the grains are not arranged in a commonly assumed mono-layer, or c) a combination of both.

Aggregating the results of Heer et al. (2012) and of Table 4 a mean empirical packing density value of $d=0.65$ is proposed. Using this value and assuming a mean grain size of $125 \mu \mathrm{m}$ it was estimated that 1,2 and $8 \mathrm{~mm}$ aliquots contain 42, 166 and 2662 grains, respectively (see Fig. S3 in the Appendix).

\section{Proportion of grains emitting luminescence}

The brightness distribution of quartz from Cueva Antón was investigated by constructing a cumulative light sum curve (Duller et al., 2000) for the natural signal $\left(L_{\mathrm{n}}\right)$ of samples CA-1 and CA-5 (Fig. 6). However, variations in grain-to-grain brightness of the natural signal can be the result of external sources of variation such as partial bleaching or beta dose heterogeneity. Therefore, a second plot was done for the natural test dose signal $\left(T_{\mathrm{n}}\right)$, where the ratio of bright to dim grains ought to be the result of inherent quartz grain characteristics. In addition, the signal intensity distribution of two quartz samples used for beta source calibration (RisoeQ and BAG478) was analysed in the same way. As both samples were thermally sensitised and homogenously dosed to $4.81 \mathrm{~Gy}$ and $8.03 \mathrm{~Gy}$, respectively, in a uniform ${ }^{60} \mathrm{Co} \gamma$-radiation field prior to this study, a smaller variation in signal intensity was expected.

The cumulative light sum curves revealed that $95 \%$ of the total natural signal intensity is emitted by $7.4 \%$ and $9.2 \%$ of the total grain population for samples CA-1 and CA-5, respectively. In combination with the estimated amount of grains on a sample disc it is estimated that the natural signal from 1,2 and $8 \mathrm{~mm}$ aliquots is mainly derived from 3,13 and 213 grains in average. Furthermore, for a typical $1 \mathrm{~mm}$ aliquot used in this study containing $40-45$ grains about $80 \%$ of the signal is likely to come from a single grain. After applying the test dose the proportions of light emitting grains increase to $13.6 \%$ and $14.3 \%$. As expected, the signal intensity distributions of the calibration quartz samples were more uniform. About $26.4 \%$ (RisoeQ) and $50.9 \%$ (BAG478) of the grains emit $95 \%$ of the bulk OSL signal. 

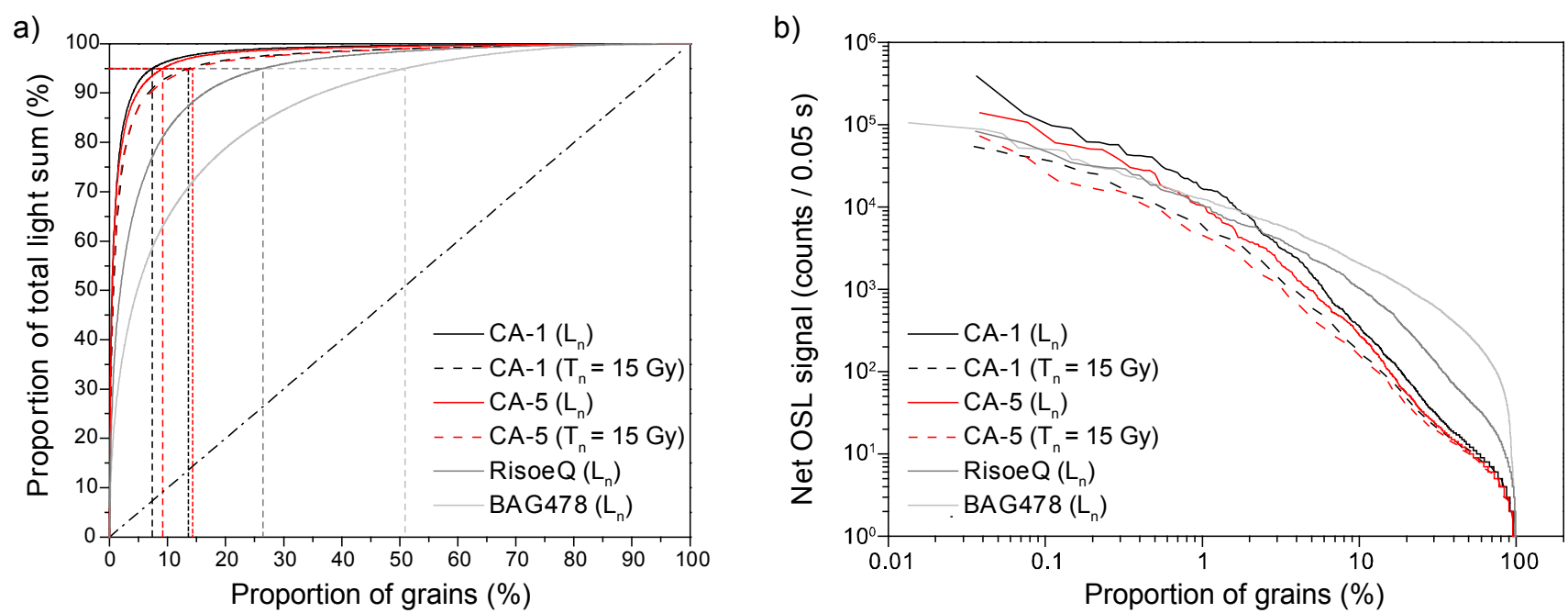

Fig. 6. Proportion of grains emitting luminescence, visualised as a) a cumulative light sum curve after Duller et al. (2000), and as b) the absolute brightness of each grain as described by Duller (2006). Both plots show the brightness distribution of the natural signal $L_{n}$ and after the natural test dose $T_{n}$ of $15 \mathrm{~Gy}$. The dashed line represents a population of grains with all grains having the same brightness. The cumulative light sum curves revealed that $95 \%$ of the total natural signal intensity is emitted by $7.4 \%$ and $9.2 \%$ of the total grain population for samples CA-1 and CA-5, respectively. A typical $1 \mathrm{~mm}$ aliquot used in this study that contains $40-45$ grains about $80 \%$ of the signal is likely to come from a single grain. After applying the test dose proportion of light emitting grains increase to $13.6 \%$ and $14.3 \%$.

\section{Presence of over-saturating grains}

The same single grain data sets used to investigate the brightness distribution were systematically surveyed for “over-saturating” ('o-s') grains (Stone and Bailey, 2012), i.e. grains with a natural signal $L_{\mathrm{n}} / T_{\mathrm{n}}$ which does not intercept the dose response curve (Yoshida et al., 2000 and Jacobs et al., 2003). This kind of behaviour has been predicted in the dose absorption model of Bailey (2004) as a result of the difference in dose rates between natural and laboratory irradiation with regard to the $R_{1}$ holetrapping centre. During natural irradiation the relatively thermally unstable $\mathrm{R}_{1}$ centre $(E=1.43 \mathrm{eV})$ is in a state of low equilibrium concentration, but in a considerably higher equilibrium concentration during laboratory irradiation. During the latter, the resulting increased competition for free electrons during irradiation effectively lowers the dose response curve so that the natural dose point, unaffected by the laboratory dose rate, can be above the fitted asymptotic signal level (Bailey, 2004).

The asymptotic regeneration value was established for those grains for which a meaningful exponential growth curve could be fitted. To identify and distinguish 'o-s' grains from those grains whose natural signal is above the dose response curve due to random counting errors, the natural signal had to be at least two standard deviations above the asymptotic regeneration value.

\section{Proportion and brightness of over-saturating grains}

Out of the 2728 grains measured in total of sample CA-1 only 20 grains $(0.73 \%)$ have shown a similar behaviour attributed to 'o-s' grains. A further 10 grains $(0.37 \%)$ were close to saturation, but had an $L_{\mathrm{n}} / T_{\mathrm{n}}$ value that still intercepted the dose response curve in the saturation area above $2 D_{0}$ and hence were not classified as 'o-s' grains. For sample CA-5 only 15 grains $(n=2598)$ were identified as 'o-s' grains $(0.58 \%)$. A comparable amount of grains $(n=16)$ had an $L_{\mathrm{n}} / T_{\mathrm{n}}$ value that intercepted the dose response curve above $2 D_{0}(0.62 \%)$. Dividing the sum of net OSL intensities of all 'o-s' grains in a sample by the total light sum revealed that the 'o-s' grains are responsible for $32 \%(\mathrm{CA}-1)$ and $11 \%(\mathrm{CA}-5)$ of the total emitted OSL signal. While on the single grain scale ' $\mathrm{o}-\mathrm{s}$ ' grains can easily be identified and discarded from further analysis, for multiple grain aliquots the presence of ' $\mathrm{o}-\mathrm{s}$ ' grains is expected to lead to an overestimation of the $D_{\mathrm{e}}$ due to their disproportional contribution to the natural signal compared to the regenerated signals (Yoshida et al., 2000). However, the impact of 'o-s' grains on multiple grain $D_{\mathrm{e}}$ estimates depends on the probability of inclusion, the degree of over-saturation and the relative brightness (Stone and Bailey, 2012). While the contribution of all ' $\mathrm{o}-\mathrm{s}$ ' grains to the total light sum appears large, the 'o-s' grain OSL intensities were found to vary in orders of magnitude. While the brightest ' $\mathrm{o}-\mathrm{s}$ ' grain of sample of CA-1 had a net OSL signal of $\sim 400000$ counts in the first $0.05 \mathrm{~s}$ of stimulation, the dimmest ' $\mathrm{o}-\mathrm{s}$ ' grain only had $\sim 400$ counts. Hence, it appears that the contribution of ' $\mathrm{o}-\mathrm{s}$ ' grains to the total light sum is not evenly shared by all 'o-s' grains, but rather dominated by a smaller fraction of disproportional bright grains.

While less than $0.8 \%$ of all measured grains were identified as 'o-s' grains and despite the low probability of an 'o-s' grain on a small aliquot $(<20 \%)$ when assuming a binomial distribution, the influence of 'o-s' grains on $D_{\mathrm{e}}$ estimates may very well increase for larger ali- 
quots. For a $1 \mathrm{~mm}$ aliquot covered by $40-63 \mu \mathrm{m}$ grains (CA-10) there is only a $18 \%$ probability that none of the 240 grains is an ' $\mathrm{o}-\mathrm{s}$ ' grain. In contrast, there is a probability of $31 \%$ of one 'o-s' grain, $26 \%$ of two 'o-s' grains and $14 \%$ of three 'o-s' grains to be present on the aliquot. For CA-1 virtually all large $8 \mathrm{~mm}$ aliquots (2662 grains per disc) contain at least five 'o-s' grains.

\section{The effect of over-saturating grains on synthetic aliquot $D_{e}$}

To further investigate the effect of ' $\mathrm{o}-\mathrm{s}$ ' grains on multiple grain $D_{\mathrm{e}}$ estimates synthetic aliquots were constructed by summing up the signals of all grains of a single grain disc where 'o-s' grains were identified. For sample CA-1 13 synthetic aliquots were constructed where each disc contained one 'o-s' grain. The relative contribution of the ' $\mathrm{o}-\mathrm{s}$ ' grain to the total light sum of each synthetic aliquot varied between 1 to $55 \%$, while the proportion of grains emitting $95 \%$ of the total light sum ranged from 6 to $28 \%$ with an average of $12.2 \pm 7.3 \%$. For three of the synthetic aliquots the 'o-s' grains were bright enough to dominate the dose response, so that no $D_{\mathrm{e}}$ could be calculated. Similar values were determined for the synthetic aliquots of sample CA-5 $(n=7)$, where the relative contribution of ' $\mathrm{o}-\mathrm{s}$ ' grains ranged from 3 to $64 \%$ and the proportion of grains emitting $95 \%$ of the total light sum varied from $3-20 \%$ with an average of $10.0 \pm 5.7 \%$. The obtained $D_{\mathrm{e}}$ values from the multiple grain synthetic aliquots were then compared to the $D_{\mathrm{e}}$ that was obtained when excluding the 'o-s' grains (Fig. 7). Exclusion of these grains revealed that the presence of ' $\mathrm{o}-$ s' on a multiple grain aliquot directly effects the calculated $D_{\mathrm{e}}$ value. After removal of the 'o-s' grains from the synthetic aliquot the maximum observed decrease in $D_{\mathrm{e}}$ was $\sim 66 \%$. It further appears that for the samples under study the relative decrease in $D_{\mathrm{e}}$ is linearly proportional to the relative contribution of the ' $\mathrm{o}-\mathrm{s}$ ' grain to the total light sum (Fig. 7). Another observation is that almost half of the identified 'o-s' grains only amount for less than $12 \%$ of the total light sum and hence lead to a decrease in $D_{\text {e }}$ of similar proportion after removal from the synthetic aliquot. Most of the remaining 'o-s' grains lead to a decrease in $D_{\mathrm{e}}$ of $10-25 \%$ after removal, while two distinct outliers more than halved the $D_{\mathrm{e}}$ of the synthetic aliquot due to their high contribution to the total light sum of about $65 \%$. As a consequence, the presence or absence of 'o-s' grains has to be considered as an additional source of intrinsic scatter between multiple grain aliquots when explaining the observed scatter in $D_{\mathrm{e}}$ distributions of the samples under study.

\section{DISCUSSION}

\section{Dose distributions}

The observed dispersion in natural dose distributions is a composite of intrinsic and extrinsic sources of error. The former arises e.g. from variations in photon counting

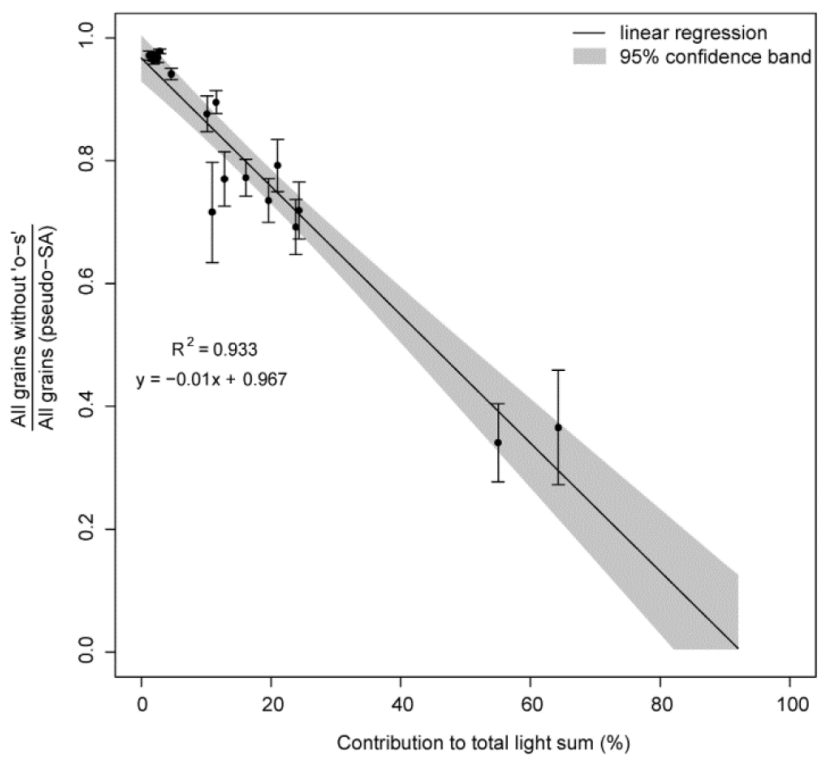

Fig. 7. Effect of over-saturating ('o-s') grains on the $D_{e}$ of synthetic multiple grain aliquots. For each of the single grain discs where an 'o-s' grain was identified the single grain signals of all grain hole positions were summed up and a $D_{e}$ value was calculated before and after excluding the 'o-s' grain from the synthetic aliquot. The decrease in $D_{e}$, expressed as the ratio of the $D_{e}$ without the 'o-s' grain and the $D_{e}$ including all grains, is plotted against the contribution of the 'o-s' grain to the total light sum of the synthetic aliquot. An apparently linear proportionality between light sum contribution and decrease in $D_{e}$ was observed for the samples under study.

statistics and curve-fitting uncertainties (Galbraith and Roberts, 2012). In the absence of any extrinsic factors such as partial bleaching, post-depositional sediment mixing or variations in beta microdosimetry, and when all intrinsic sources of uncertainty have been determined and properly accounted for, no spread in dose distributions should be observed. However, it is common that even in dose recovery experiments, where any extrinsic sources of scatter that affect natural samples are effectively excluded, and after taking all intrinsic errors into account, a substantial spread in $D_{\mathrm{e}}$ values remains (Galbraith et al., 2005).

To assess whether the assigned uncertainties on the individual $D_{\mathrm{e}}$ estimates are sufficient to explain the observed variability we calculated the overdispersion using the central age model. For the quartz samples OD values ranged from $11 \%$ to $33 \%$. The general assumption of less variation in $D_{\mathrm{e}}$ with an increasing number of simultaneously measured grains (Duller, 2008 and Arnold and Roberts, 2009) also applied to this study (Fig. S4 in the Appendix). Single grain $D_{\mathrm{e}}$ distributions exhibit the highest mean OD (29\%), which continuously decreases for multi grain aliquots with increasing number of simultaneously measured grains. The decrease in OD approximately follows the prediction of Cunningham et al. (2011). However, in terms of absolute values, the observed OD in single grain and multiple grain $D_{\mathrm{e}}$ distribu- 
tions is higher than those summarised in Arnold and Roberts (2009). In any case, the calculated OD values hence indicate that the observed spread in dose distributions cannot be explained by intrinsic uncertainties alone. This may either be due to the fact that the intrinsic variability has been underestimated or that additional intrinsic and extrinsic sources of scatter have to be considered.

\section{Extrinsic sources of uncertainty}

Samples analysed in this study are known to be of fluvial origin (Angelucci et al., 2013), hence partial bleaching might affect the $D_{\mathrm{e}}$ distributions to some extent. However, LM-OSL measurements have shown a clear dominance of the fast component and routine assessment of $D_{\mathrm{e}}(t)$ plots (Bailey, 2003) constructed for samples CA-1, CA-2 and CA-6 on different aliquot sizes and single quartz grains provide no evidence for a significant dependence of $D_{\mathrm{e}}$ on the integration interval over the initial part of the signal. Contamination of the integrated OSL signal used for $D_{\mathrm{e}}$ determination by a partially bleached medium component is hence regarded unlikely. Another method for identifying partial bleaching of quartz from samples CA-1 and CA-5 was applied by measuring the much harder-to-bleach pIRIR signals of feldspars (Thomsen et al., 2008b and Buylaert et al., 2012; see Fig. S5 in the Appendix). As dose rates to quartz and feldspar and hence the $D_{\mathrm{e}}$ differ due to the internal K-content of feldspar we calculated the age of these samples in order to compare the OSL and pIRIR results. Prior to that residual doses of 3.7 Gy and 11.4 Gy, determined on the modern sample CA-7, were subtracted from the pIRIR 225 and pIRIR 290 equivalent dose,
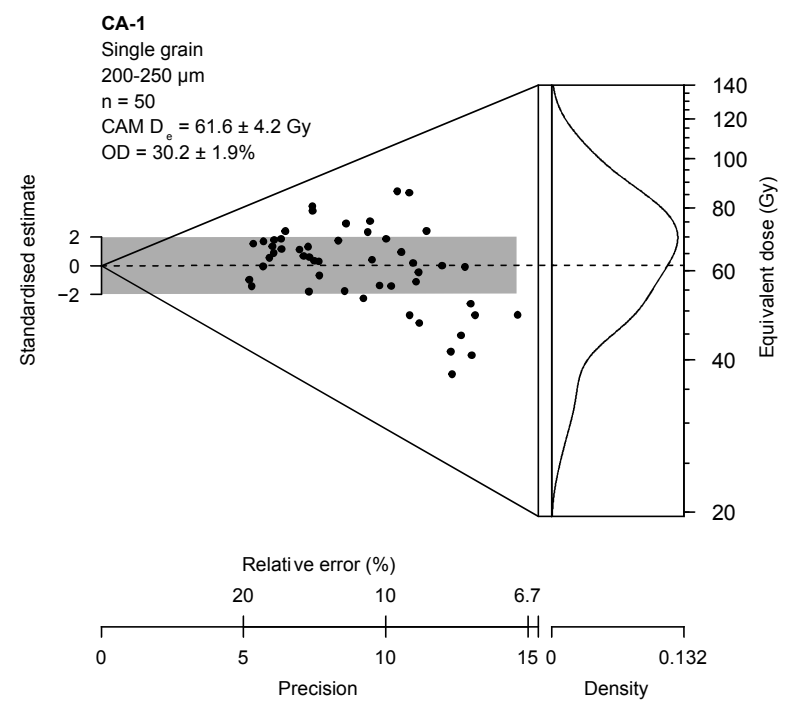

respectively. Applying the homogeneity test after Galbraith (2003) indicates that the pIRIR 290 age $(74.1 \pm 7.9$ ka) for sample CA-1 almost perfectly agrees $(P=0.96)$ with the quartz OSL ages $(70.9 \pm 7.6 \mathrm{ka}$ and $74.1 \pm 7.9$ ka). However, the pIRIR 225 age $(54.5 \pm 4.9 \mathrm{ka})$ seems to underestimate the burial age $(P=0.06)$. For sample CA-5 the $\operatorname{pIRIR}_{225}$ age $(83.7 \pm 8.9 \mathrm{ka})$ is slightly larger than the quartz OSL age estimates $(69.9 \pm 7.6 \mathrm{ka}$ and $68.7 \pm 6.8$ $\mathrm{ka})$, but all age estimates still agree with each other $(P=$ 0.36). The pIRIR 290 signal is regarded to yield the more reliable age estimate due to its higher stability over the pIRIR $_{25}$ signal (Thiel et al., 2011; Thomsen et al., 2011 and Buylaert et al., 2012). Note that no additional tests to correct for anomalous fading (e.g. Huntley and Lamothe, 2001; Auclair et al., 2003 and Kars et al., 2008) were conducted as fading correction methods are problematic (e.g. Wallinga et al., 2007 and Reimann et al., 2011). However, since the quartz OSL age estimates from single grains and small aliquots perfectly agree with the age derived from the much harder-to-bleach pIRIR 290 signal, this gives strong support to a well-bleached quartz OSL signal. This confirms the assumption that partial bleaching is not necessarily an impediment to obtaining accurate chronologies for Late Pleistocene alluvial samples (Jain et al., 2004; Martins et al., 2010; Sohbati et al., 2012 and Medialdea et al., 2014).

Another source of extrinsic variability might arise from post-depositional sediment mixing that is often associated with archaeological deposits (cf. Jacobs and Roberts, 2007). However, the single grain $D_{\mathrm{e}}$ distributions from sample CA-1 and CA-5 provide no evidence for distinct dose components that might be related to the intrusion of younger or older grains (Fig. 8). The lack of
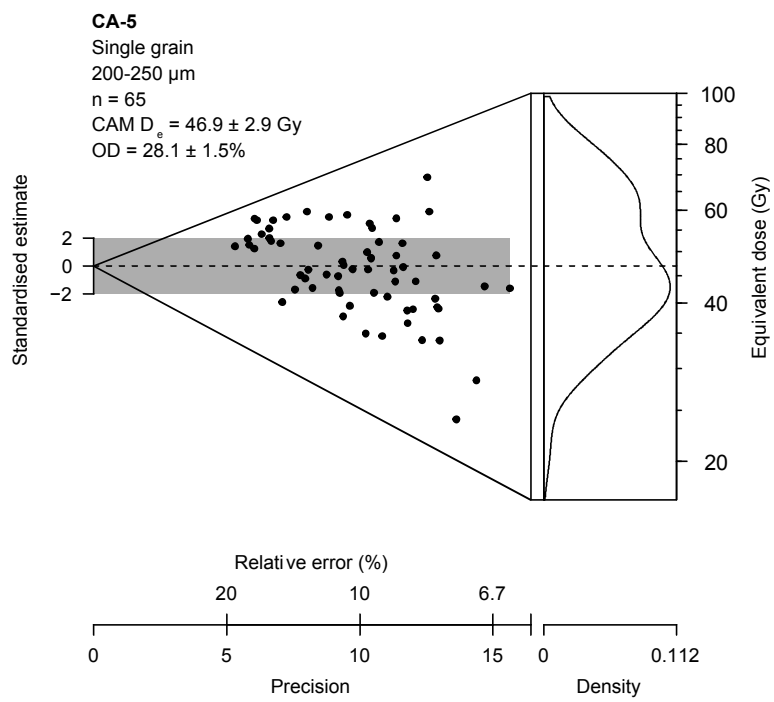

Fig. 8. Single grain $D_{e}$ distributions of samples CA-1 and CA-5 visualised in a combined radial plot (Galbraith, 1988) and kernel density estimate (KDE) plot, generated with the plot_AbanicoPlot() function of the $R$ package 'Luminescence' (Kreutzer et al., 2012). The grey bar in the radial plot is centred on the weighted $D_{e}$ calculated by the central age model (CAM, Galbraith et al., 1999). The calculated overdispersion values indicate that the observed spread in the dose distributions cannot be explained by intrinsic uncertainties alone. 
post-depositional modifications at Cueva Antón is also confirmed by Angelucci et al. (2013). The use of a finite mixture model (Galbraith and Green, 1990 and Roberts et al., 2000) was hence considered to be inappropriate.

The observed spread in the dose distributions may also partly be explained by small-scale variations in the beta radiation dose to which the samples have been exposed during burial (Olley et al., 1997 and Duller, 2008). Modelling studies (e.g. Nathan et al., 2003) have shown that beta heterogeneity may significantly influence $D_{\mathrm{e}}$ distributions. However, there is no straightforward method to identify beta dose heterogeneities and their impact on dose estimates (cf. Guérin et al., 2013). At this stage we cannot assess whether the observed overdispersion can at least partly been explained by microdosimetry or not. Considering that our samples were probably not affected by partial bleaching, the CAM may yield the most appropriate burial dose estimate if beta dose heterogeneity is probable (Guérin et al., 2013).

\section{Intrinsic sources of uncertainty}

While extrinsic sources of error potentially account for some of the observed scatter, further intrinsic factors may have not been accounted for yet. While low OSL intensity of quartz (cf. Duller, 2006; Preusser et al., 2006 and Klasen et al., 2007) as a source of additional scatter to $D_{\mathrm{e}}$ distributions can be excluded due to the bright signals, it was shown that even for heated and homogenously irradiated quartz an OD of $8-12 \%$ remained in single grain $D_{\mathrm{e}}$ datasets after correcting for the spatial nonuniformity of the beta sources. This additional intrinsic uncertainty is comparable to values reported earlier by Thomsen et al. (2005, 2007) and Reimann et al. (2012b). However, unlike Thomsen et al. (2007) and Reimann et al. (2012b) we did not add this uncertainty onto the uncertainties of the single grain $D_{\mathrm{e}}$ estimates because this value was derived from a gamma dose recovery experiment for calibrating the beta sources on calibration samples of different provenance.

Beyond that, recent single grain studies have demonstrated that different 'grain behavioural types' with regard to luminescence properties such as brightness and doseresponse characteristics can have a significant impact on both single and multiple grain dose distributions and have to be considered as additional sources of intrinsic scatter (e.g. Yoshida et al., 2000; Duller, 2012; Stone and Bailey, 2012 and Demuro et al., 2008, 2013). By single grain measurements the variability of the saturation dose $D_{0}$ and the presence of 'over-saturating' was investigated. The former has been reported to affect the ability to successfully recover a laboratory dose in a dose recovery experiment as the given dose approaches or exceeds the saturation dose (Duller, 2012). A mean $D_{0}$ of $\sim 63$ Gy was determined for quartz from Cueva Antón, which falls within the range of saturation doses of quartz reported in Wintle and Murray (2006). Despite the large variability of $D_{0}$ values similar to the values reported by Duller
(2012) all conducted dose recovery experiments on single grains and multiple grain aliquots performed well (Table $3)$. Hence, the observed variability in $D_{0}$ values is not expected problematic for the samples from Cueva Antón.

Following the suggestion of Stone and Bailey (2012) the single grain data sets were monitored for the presence of 'o-s' grains. By making synthetic aliquots consisting of 100 grains each it was assessed that most 'o-s' grains only have a minor influence on the calculated $D_{\text {e }}$. However, some 'o-s' grains more than doubled the $D_{\mathrm{e}}$ or were even so bright to saturate the synthetic aliquot so that no $D_{\text {e }}$ could be calculated. While 'o-s' grains are easily rejected from single grain data sets, there is no formal indication whether a multiple grain aliquot and its $D_{\mathrm{e}}$ that otherwise passes all rejection criteria is affected by the presence of one or more 'o-s' grains. Hence, for multiple grain aliquots systematically higher $D_{\mathrm{e}}$ and age estimates should be expected (Stone and Bailey, 2012). However, statistically indistinguishable single grain and small aliquot CAM $D_{\mathrm{e}}$ estimates of $61.6 \pm 4.2$ Gy and $61.5 \pm 3.4 \mathrm{~Gy}$ for $\mathrm{CA}-1$ and $46.9 \pm 2.9$ Gy and $48.9 \pm 2.8$ Gy for CA-5, respectively, were obtained. It is only for the $8 \mathrm{~mm}$ aliquots of CA-1 that a significantly higher mean $D_{\mathrm{e}} 74.7 \pm 4.3$ Gy was calculated. A similar behaviour was observed for sample CA-10, where $1 \mathrm{~mm}$ aliquots covered with $100-150 \mu \mathrm{m}$ quartz grains yielded a $D_{\mathrm{e}}$ of $44.4 \pm 2.7 \mathrm{~Gy}$, but where the same aliquot size covered with 40-63 $\mu \mathrm{m}$ quartz grains yielded a considerably higher $D_{\mathrm{e}}$ of $62.4 \pm 3.6 \mathrm{~Gy}$. Assuming that the $D_{\mathrm{e}}$ increase can indeed be attributed to the presence of ' $\mathrm{o}-\mathrm{s}$ ' grains, they would be responsible for an increase of about 12-18 Gy. Considering that single grain and small aliquot $D_{\mathrm{e}}$ distributions of CA-1 and CA-5 yield indistinguishable mean $D_{\mathrm{e}}$ estimates it appears that the presence of 'o-s' grains only has a relevant impact for larger aliquots (cf. Stone and Bailey, 2012).

While it is not possible to definitely state the causes for the observed spread in data and the $D_{\mathrm{e}}$ and age overestimation of larger multiple grain aliquots, the single grain and synthetic aliquot analyses indicate that multiple grain averaging effects are a complex system of various (aberrant) OSL signal characteristics. Here, these problematic averaging effects seem to become noticeable when the number of simultaneously measured grains exceeds a certain threshold value. Small aliquot $D_{\mathrm{e}}$ estimates are seemingly not affected by the presence of ' 0 -s' grains, which might be the result of a low probability of having an 'o-s' grain and an overall low percentage of bright grains that contribute to the total light sum. When a small aliquot contains one or more very bright ' $\mathrm{o}-\mathrm{s}$ ' grains, which have been shown to have the highest impact on the $D_{\mathrm{e}}$ about equal to their share of the total light sum, there is a higher probability that the ' $\mathrm{o}-\mathrm{s}$ ' grain even saturates the small aliquot with only a few other grains. As a result, the small aliquot would not pass the rejection criteria. But as the amount of simultaneously measured grains increases, it is less likely that the 'o-s' grains is 
able to saturate the multiple grain aliquot. Depending on its relative contribution to the multiple grain OSL signal the 'o-s' may then lead to a systematic overestimation of the equivalent dose.

\section{Palaeodose and age estimates}

Concluding the previous sections we consider the CAM as the most appropriate age model to calculate an equivalent dose representative for the 'true' burial age of the samples from Cueva Antón. Furthermore, only the quartz single grain and small aliquot $(1 \mathrm{~mm}$ and $2 \mathrm{~mm}$ with $100-150 / 200 \mu \mathrm{m}$ grains) data sets are considered to yield reliable age estimates, as larger aliquots are supposedly affected by a systematic overestimation of the $D_{\mathrm{e}}$ due to the presence and influence of over-saturating grains. CAM $D_{\mathrm{e}}$ estimates obtained from these data sets show only little variation on a sample-to-sample basis and no obvious correlation with sample depth or stratigraphic order. The CAM $D_{\mathrm{e}}$ values range from $44 \mathrm{~Gy}$ to $75 \mathrm{~Gy}$ and yield luminescence ages between $69 \mathrm{ka}$ and $82 \mathrm{ka}$. Results of equivalent dose determination and age calculation are summarised in Table 5.

\section{Archaeological and sedimentological implications}

A coherent quartz OSL-based chronostratigraphy for the archaeological succession (AS2-AS5) at Cueva Antón is provided (Fig. 9). Due to the highly significant agreement of age estimates $(P=0.95)$, an error weighted mean and associated standard deviation of $71.0 \pm 1.8 \mathrm{ka}$ is suggested for unit II-e. Likewise, weighted mean ages of $69.2 \pm 0.9 \mathrm{ka}(P=0.91)$ and $72.1 \pm 5.8 \mathrm{ka}(P=0.42)$ for unit III-f and III-m are suggested, respectively. Taking all age estimates into account, the high agreement of age estimates $(P=0.99)$ reduces to an error weighted mean of $72.0 \pm 4.2 \mathrm{ka}$ for sub-complexes AS2 to AS5.

The age estimates for unit II-e $(\sim 71 \mathrm{ka})$ at the top of AS2 clearly contradicts the ABA radiocarbon age of $39.7 \pm 0.6$ ka BP ( 43.5 ka cal BP, OxA-18672; Zilhão et al., 2010) obtained from the underlying unit II-h/i. How- ever, the radiocarbon date is regarded as a preliminary minimum age estimate for unit II-h/i (Zilhão et al., 2010).

The very low variation in quartz OSL age estimates throughout the entire archaeological succession suggests a fairly rapid fluvial accumulation of the sediments, which is in very good accord with the sedimentological and micromorphological findings of Angelucci et al. (2013). However, given that all age estimates are statistically indistinguishable it is neither possible to discern individual flood events nor to constrain the involved time span.

Furthermore, the suggested time frame for the deposition of the middle to lower part of the alluvial succession also implies a major hiatus between sub-complexes AS2 and AS1, which are separated by an erosional cut. However, the interpretation of such a large hiatus in the sedimentary record remains open and requires additional investigation.

\section{CONCLUSIONS}

The aim of this study was to establish a reliable chronostratigraphy for the archaeological succession from sub-complexes AS2 to AS5 of Cueva Antón. For that purpose, the most reliable luminescence dating technique for estimating the age of fluvial deposits in a rock shelter was ascertained through a series of laboratory experiments and by cross-validating the performance of the dating methods used.

From a methodological perspective the following conclusions can be drawn: i) The multiple grain approach utilising quartz grains on small (preferably $1 \mathrm{~mm}$ ) aliquots is a viable method to determine the burial age of fluvial deposits in rock shelters that are unaffected by post-depositional mixing. ii) While the same results on the interpretation of the succession at Cueva Antón would have been achieved if exclusively small aliquots were used, single grain measurements of quartz provided valuable information for the analysis of $D_{\mathrm{e}}$ distributions. Statistically indistinguishable $D_{\mathrm{e}}$ and age estimates from

Table 5. Results of equivalent dose determination and age calculation. $Q=$ quartz.

\begin{tabular}{|c|c|c|c|c|c|c|c|c|c|c|}
\hline Unit Lab. & Sample & Mineral & $\begin{array}{c}\text { Aliquot } \\
\text { diameter } \\
(\mathrm{mm})\end{array}$ & $\begin{array}{c}\text { Grain size } \\
\text { fraction } \\
(\mu \mathrm{m})\end{array}$ & $\begin{array}{c}\mathrm{Nr} \text { of } \\
\text { aliquots/grains } \\
\text { accepted/measured }\end{array}$ & $\begin{array}{l}\text { Age } \\
\text { model }\end{array}$ & $\begin{array}{c}\text { Over- } \\
\text { dispersion } \\
(\%)\end{array}$ & $\begin{array}{l}\text { Equivalent } \\
\text { dose } \\
\text { (Gy) }\end{array}$ & $\begin{array}{c}\text { Total dose } \\
\text { rate } \\
\left(\mathrm{Gy} \mathrm{ka}^{-1}\right)\end{array}$ & $\begin{array}{c}\text { Luminescence } \\
\text { age } \\
\text { (ka) }\end{array}$ \\
\hline \multirow[t]{2}{*}{ II-e C-L2941 } & CA-1 & $Q$ & 2 & $100-150$ & $42 / 50$ & CAM & $15.3 \pm 0.7$ & $61.5 \pm 3.4$ & $0.87 \pm 0.10$ & $70.9 \pm 7.6$ \\
\hline & & $Q$ & SG & $200-250$ & $50 / 3100$ & CAM & $30.2 \pm 1.9$ & $61.6 \pm 4.2$ & $0.84 \pm 0.11$ & $72.9 \pm 7.7$ \\
\hline II-e C-L3137 & CA-2 & Q & 1 & $100-150$ & $51 / 60$ & CAM & $29.3 \pm 1.6$ & $66.9 \pm 4.4$ & $0.97 \pm 0.12$ & $69.3 \pm 7.7$ \\
\hline II-ø C-L3375 & CA-9 & $\bar{Q}$ & 1 & $100-150$ & $46 / 58$ & CAM & $22.6 \pm 1.2$ & $55.0 \pm 3.3$ & $0.67 \pm 0.08$ & $82.2 \pm 8.0$ \\
\hline II-y C-L2942 & CA-4 & $Q$ & 2 & $100-200$ & $41 / 48$ & CAM & $17.0 \pm 0.8$ & $75.1 \pm 4.3$ & $1.08 \pm 0.13$ & $69.4 \pm 7.2$ \\
\hline \multirow[t]{3}{*}{ III-f C-L2943 } & CA-5 & $Q$ & 2 & $100-200$ & $45 / 48$ & CAM & $17.9 \pm 0.8$ & $48.9 \pm 2.8$ & $0.70 \pm 0.09$ & $69.9 \pm 7.6$ \\
\hline & & $Q$ & SG & $200-250$ & $65 / 2800$ & CAM & $28.1 \pm 1.5$ & $46.9 \pm 2.9$ & $0.68 \pm 0.08$ & $68.7 \pm 6.8$ \\
\hline & & $Q$ & 1 & $100-150$ & $46 / 62$ & CAM & $23.5 \pm 1.3$ & $44.4 \pm 2.7$ & $0.62 \pm 0.08$ & $72.2 \pm 7.8$ \\
\hline III-k/IC-L3377 & CA-11 & $\bar{Q}$ & 1 & $100-150$ & $60 / 84$ & CAM & $27.1 \pm 1.3$ & $49.0 \pm 3.0$ & $0.66 \pm 0.08$ & $74.1 \pm 7.9$ \\
\hline III-mC-L3138 & CA-6 & Q & 1 & $100-150$ & $66 / 84$ & CAM & $32.7 \pm 1.7$ & $66.9 \pm 4.3$ & $0.86 \pm 0.12$ & $77.5 \pm 9.8$ \\
\hline III-mC-L3378 & CA-12 & $Q$ & 1 & $100-150$ & $45 / 70$ & CAM & $25.0 \pm 1.4$ & $58.4 \pm 3.7$ & $0.85 \pm 0.10$ & $69.1 \pm 7.3$ \\
\hline
\end{tabular}




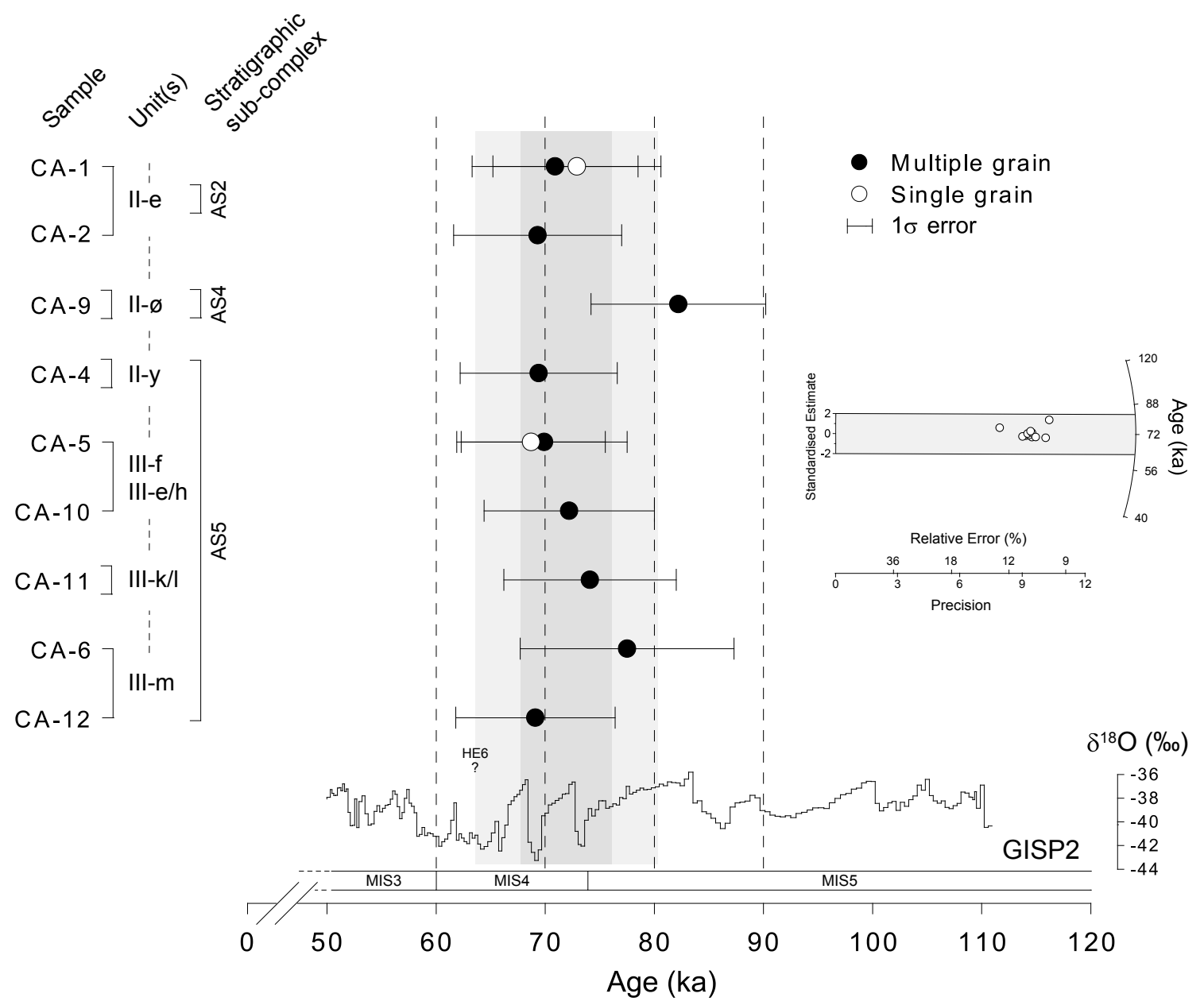

Fig. 9. OSL chronostratigraphy for the archaeological succession (AS2-AS5) at Cueva Antón using multiple and single grains of quartz. GISP2 oxygen isotope curve from Grootes et al. (1993) with timescale of Meese et al. (1997). Approximate timing of Heinrich Event 6 (HE 6) taken from Hemming (2004) (see also Cayre et al., 1999 and references therein). Dashed lines on y-axis denote unlisted archaeological units (see Angelucci et al., 2013 for a comprehensive list). Grey bars on x-axis are the standard deviation (dark) and twice the standard deviation (light) on the error weighted mean of all age estimates. Inset: Radial plot (Galbraith, 1988) of quartz OSL age estimates. The reference value is the error weighted mean of age estimates. The grey bar denotes the $2 \sigma(95 \%$ confidence interval) band on the reference value.

single grains and small aliquots give strong support for the potential of small aliquot measurements for studies in comparable contexts. Furthermore, single grain measurements allowed the detection of aberrant grain behaviour and by constructing synthetic aliquots their impact on multiple grain $D_{\mathrm{e}}$ estimates could be quantified. iii) The presence of 'over-saturating' grains, i.e. grains whose natural signal is significantly above the dose response curve, affected multiple grain $D_{\mathrm{e}}$ estimates and can lead to a systematic overestimation of the $D_{\mathrm{e}}$ as the number of simultaneously measured grains increases. Besides the probability of having an ' $\mathrm{o}-\mathrm{s}$ ' grain on the aliquot, the degree of overestimation appears to be primarily controlled by the relative contribution of the ' $\mathrm{O}-\mathrm{s}$ ' grain to the total light sum of a multiple grain aliquot. iv)
The comparison of different luminescence dating techniques utilising different minerals and luminescence signals with varying bleaching rates is a powerful tool to identify partial bleaching and to strengthen the reliability of the obtained chronologies (cf. Murray et al., 2012).

Finally, the results of the present study are a valuable contribution to the chronological framework and interpretation of the Middle to Upper Palaeolithic transition in the Iberian Peninsula. The quartz OSL chronology for the middle to lower parts of the fluvial succession at Cueva Antón suggests a fairly rapid deposition of the sediments during late MIS 5 and possibly throughout MIS 4. Consequently, Mousterian occupations of the rock shelter primarily documented in the lower parts of the succession fall within that particular time frame. 


\section{APPENDIX}

Five figures are available as Supplementary Material in electronic version of this article at http://dx.doi.org/10.1515/geochr-2015-0010. Fig. S1: 3D Plots of beta source dose rate distributions from three Risø TL/OSL readers; Fig. S2: Deconvolved LM-OSL curves from samples CA-1 and CA-6; Fig. S3: Number of mineral grains on a sample disc as a function of the aliquot diameter, mean grain size and packing density; Fig. S4: Dependency of overdispersion on the amount of grains on a sample disc; Fig. S5: Bleaching rates of the pIRIR $_{225}$ and pIRIR 290 signals from sample CA-1.

\section{ACKNOWLEDGEMENTS}

Archaeological fieldwork and research at Cueva Antón were funded, over the years, by the Fundación Séneca (Murcia), the University of Murcia, the Spanish Ministerio de Ciencia e Innovación (grant HAR201124878), the Leakey Foundation, the Dirección General del Medio Natural de la Región de Murcia and the Municipality of Mula, and actively supported by the Museo de Arte Ibérico El Cigarralejo de Mula. We are grateful for the financial support by the $\mathrm{C} 1$ and $\mathrm{F} 2$ projects of the CRC 806 "Our Way To Europe. Culture-Environment Interaction and Human Mobility in the Late Quaternary", funded by the German Research Foundation (DFG). Melanie Bartz is thanked for providing additional data on the amount of grains on a sample disc.

\section{REFERENCES}

Aitken MJ, 1985. Thermoluminescence Dating. Academic Press, London.

Angelucci DE, Anesin D, Susini D, Villaverde V, Zapata J and Zilhão J, 2013. Formation processes at a high resolution Middle Paleolithic site: Cueva Antón (Murcia, Spain). Quaternary International 315: 24-41, DOI 10.1016/j.quaint.2013.03.014.

Arnold LJ and Roberts RG, 2009. Stochastic modelling of multi-grain equivalent dose $\left(D_{e}\right)$ distributions: Implications for OSL dating of sediment mixtures. Quaternary Geochronology 4: 204-230, DOI 10.1016/j.quageo.2008.12.001.

Arnold LJ, Demuro M and Navazo Ruiz M, 2012. Empirical insights into multi-grain averaging effects from 'pseudo' single-gran OSL measurements. Radiation Measurements 47: 652-658, DOI 10.1016/j.radmeas.2012.02.005.

Auclair M, Lamothe M and Hout S, 2003. Measurement of anomalous fading for feldspar IRSL using SAR. Radiation Measurements 37: 487-492, DOI 10.1016/S1350-4487(03)00018-0.

Bailey RM, 2003. Paper I: The use of measurement-time dependent single-aliquot equivalent-dose estimates from quartz in the identification of incomplete signal resetting. Radiation Measurements 37: 673-683, DOI 10.1016/S1350-4487(03)00078-7.

Bailey RM, 2004. Paper I - simulation of dose absorption in quartz over geological timescales and its implications for the precision and accuracy of optical dating. Radiation Measurements 38: 299-310, DOI 10.1016/j.radmeas.2003.09.005.

Ballarini M, Wintle AG and Wallinga J, 2006. Spatial variation of dose rate from beta sources as measured using single grains. Ancient TL 24(1): 1-8.
Bøtter-Jensen L, 1997. Luminescence techniques: instrumentation and methods. Radiation Measurements 27(5/6): 749-768, DOI 10.1016/S1350-4487(97)00206-0.

Bøtter-Jensen L, Duller GAT, Murray AS and Banerjee D, 1999. Blue light emitting diodes for optical stimulation of quartz in retrospective dosimetry and dating. Radiation Protection Dosimetry 84: 335-340.

Bøtter-Jensen L, Bulur E, Duller GAT and Murray AS, 2000. Advances in luminescence instrument systems. Radiation Measurements 32: 523-528, DOI 10.1016/S1350-4487(00)00039-1.

Bøtter-Jensen L, Andersen CE, Duller GAT and Murray AS, 2003. Developments in radiation, stimulation and observation facilities in luminescence measurements. Radiation Measurements 37: 535541, DOI 10.1016/S1350-4487(03)00020-9.

Bøtter-Jensen L, Thomsen KJ and Jain M, 2010. Review of optically stimulated luminescence (OSL) instrumental developments for retrospective dosimetry. Radiation Measurements 45: 253-257, DOI 10.1016/j.radmeas.2009.11.030

Brock F, Higham T, Ditchfield P and Ramsey CB, 2010. Current pretreatment methods for AMS radiocarbon dating at the Oxford Radiocarbon Accelerator Unit (ORAU). Radiocarbon 52(1): 103112.

Buylaert J-P, Murray AS, Thomsen KJ and Jain M, 2009. Testing the potential of an elevated temperature IRSL signal from K-feldspar. Radiation Measurements 44(5): 560-565, DOI 10.1016/j.radmeas.2009.02.007.

Buylaert J-P, Jain M, Murray AS, Thomsen KJ, Thiel C and Sohbati R, 2012. A robust feldspar luminescence dating method for Middle and Late Pleistocene sediments. Boreas 41: 435-451, DOI 10.1111/j.1502-3885.2012.00248.x.

Chang H-C and Wang L-C, 2010. A simple proof of Thue's Theorem on Circle Packing. WEB site: <http://arxiv.org/pdf/1009.4322v1.pdf>. Accessed 2014 July 24.

Cunningham AC, Wallinga J and Minderhoud PSJ, 2011. Expectations of scatter in equivalent-dose distributions when using multi-grain aliquots for OSL dating. Geochronometria 38(4): 424-431, DOI 10.2478/s13386-011-0048-z.

Cayre O, Lancelot Y and Vincent E, 1999. Paleoceanographic reconstruction from planktonic foraminifera off the Iberian Margin: Temperature, salinity, and Heinrich events. Paleoceanography 14(3): 384-396, DOI 10.1029/1998PA900027.

Demuro M, Roberts RG, Froese DG, Arnold LJ, Brock F and Bronk Ramsey C, 2008. Optically stimulated luminescence dating of single and multiple grains of quartz from perennially frozen loess in western Yukon Territory, Canada: Comparison with radiocarbon chronologies for the late Pleistocene Dawson tephra. Quaternary Geochronology 3: 346-364, DOI 10.1016/j.quageo.2007.12.003.

Demuro M, Arnold LJ, Froese DG and Roberts RG, 2013. OSL dating of loess deposits bracketing Sheep Creek tephra beds, northwest Canada: Dim and problematic single-grain OSL characteristics and their effect on multi-grain age estimates. Quaternary Geochronology 15: 67-87, DOI 10.1016/j.quageo.2012.11.003.

Duller GAT, 2003. Distinguishing quartz and feldspar in single grain luminescence measurements. Radiation Measurements 37: 161165, DOI 10.1016/S1350-4487(02)00170-1.

Duller GAT, 2006. Single grain optical dating of glacigenic deposits. Quaternary Geochronology 1: 296-304, DOI 10.1016/i.quageo.2006.05.018.

Duller GAT, 2008. Single-grain optical dating of Quaternary sediments: why aliquot size matters in luminescence dating. Boreas 37: 589612, DOI 10.1111/j.1502-3885.2008.00051.x.

Duller GAT, 2012. Improving the accuracy and precision of equivalent doses determined using the optically stimulated luminescence signal from single grains of quartz. Radiation Measurements 47: 770777, DOI 10.1016/j.radmeas.2012.01.006.

Duller GAT, Bøtter-Jensen L, Murray AS and Truscott AJ, 1999. Single grain laser luminescence (SGLL) measurements using a novel automated reader. Nuclear Instruments and Methods in Physics Research B 155: 506-514, DOI 10.1016/S0168-583X(99)00488-7.

Duller GAT, Bøtter-Jensen L and Murray AS, 2000. Optical dating of single sand-sized grains of quartz: sources of variability. Radiation 
Measurements 32: 453-457, DOI 10.1016/S1350-4487(00)00055$\mathrm{X}$.

Dunne J, Elmore D and Muzikar P, 1999. Scaling factors for the rates of production of cosmogenic nuclides for geometric shielding and attenuation at depth on sloped surfaces. Geomorphology 27: 3-11, DOI 10.1016/S0169-555X(98)00086-5.

Fletcher WJ and Sánchez Goñi MF, 2008. Orbital- and sub-orbital-scale climate impacts on vegetation of the western Mediterranean basin over the last 48,000 yr. Quaternary Research 70: 451-464, DOI 10.1016/j.yqres.2008.07.002.

Galbraith RF, 1988. Graphical Display of Estimates Having Differing Standard Errors. Technometrics 30(3): 271-281, DOI 10.1080/00401706.1988.10488400.

Galbraith RF, 2003. A simple homogeneity test for estimates of dose obtained using OSL. Ancient TL 21(2): 75-77.

Galbraith RF and Green PF, 1990. Estimating the component ages in a finite mixture. Nuclear Tracks and Radiation Measurements 17(3): 197-206, DOI 10.1016/1359-0189(90)90035-V.

Galbraith RF and Roberts RG, 2012. Statistical aspects of equivalent dose and error calculation and display in OSL dating: An overview and some recommendations. Quaternary Geochronology 11: 1-27, DOI 10.1016/j.quageo.2012.04.020.

Galbraith RF, Roberts RG, Laslett GM, Yoshida H and Olley JM, 1999. Optical dating of single and multiple grains of quartz from Jinmium rock shelter, Northern Australia: Part I, Experimental design and statistical models. Archaeometry 41(2): 339-364, DOI 10.1111/j.1475-4754.1999.tb00987.x.

Galbraith RF, Roberts RG and Yoshida H, 2005. Error variation in OSL palaeodose estimates from single aliquots of quartz: a factorial experiment. Radiation Measurements 39: 289-307, DOI 10.1016/j.radmeas.2004.03.023.

Grootes PM, Stuiver M, White JWC, Johnsen S and Jouzel J, 1993. Comparison of oxygen isotope records from the GISP2 and GRIP Greenland ice cores. Nature 366: 552-554, DOI $10.1038 / 366552 \mathrm{a} 0$.

Guérin G, Mercier N and Adamiec G, 2011. Dose-rate conversion factors: update. Ancient TL 29(1): 5-8.

Guérin G, Murray AS, Jain M, Thomsen KJ and Mercier N, 2013. How confident are we in the chronology of the transition between Howieson's Poort and Still Bay? Journal of Human Evolution 64: 314317, DOI 10.1016/j.jhevol.2013.01.006.

Heer AJ, Adamiec G and Moska P, 2012. How many grains are there on a single aliquot? Ancient TL 30(1): 9-16.

Hemming SR, 2004. Heinrich Events: Massive Late Pleistocene detritus layer of the north Atlantic and their global climate imprint. Reviews of Geophysics 42: RG1005, DOI 10.1029/2003RG000128.

Higham T, 2011. European Middle to Upper Palaeolithic radiocarbon dates are often older than they look: Problems with previous dates and some remedies. Antiquity 85(327): 235-249.

Higham T, Brock F, Peresani M, Broglio A, Wood R and Douka K, 2009. Problems with radiocarbon dating the Middle to Upper Palaeolithic transition in Italy. Quaternary Science Reviews 28: 12571267, DOI 10.1016/j.quascirev.2008.12.018.

Huang W and Ye T, 2011. Global optimization method for finding dense packings of equal circles in a circle. European Journal of Operational Research 210(3): 474-481, DOI 10.1016/j.ejor.2010.11.020.

Huntley DJ and Baril MR, 1997. The K content of the K-feldspars being measured in optical dating or in thermoluminescence dating. Ancient TL 15(1): 11-13.

Huntley DJ and Lamothe M, 2001. Ubiquity of anomalous fading in Kfeldspars and the measurement and correction for it in optical dating. Canadian Journal of Earth Sciences 38: 1093-1106, DOI 10.1139/cjes-38-7-1093.

Huntley DJ, Godfrey-Smith DI and Thewalt MLW, 1985. Optical dating of sediments. Nature 313: 105-107, DOI 10.1038/313105a0.

IGME, 1972. Mapa Geológico de España. Escala 1:50.000. 912(26-36). Mula. Instituto Geológico y Minero de España, Madrid.

Jacobs Z and Roberts RG, 2007. Advances in Optically Stimulated Luminescence Dating of Individual Grains of Quartz from Archeo- logical Deposits. Evolutionary Anthropology 16: 210-223, DOI 10.1002/evan.20150.

Jacobs Z, Duller GAT and Wintle AG, 2003. Optical dating of dune sand from Blombos Cave, South Africa: II - single grain data. Journal of Human Evolution 44: 613-625, DOI 10.1016/S00472484(03)00049-6.

Jain M, Murray AS and Bøtter-Jensen L, 2004. Optically stimulated luminescence dating: how significant is incomplete light exposure in fluvial environments?. Quaternaire 15(1/2): 143-157.

Jöris $\mathrm{O}$ and Street $\mathrm{M}, 2008$. At the end of the ${ }^{14} \mathrm{C}$ time scale - the Middle to Upper Paleolithic record of western Eurasia. Journal of Human Evolution 55: 782-802, DOI 10.1016/j.jhevol.2008.04.002.

Kars $\mathrm{RH}$, Wallinga $\mathrm{J}$ and Cohen KM, 2008. A new approach towards anomalous fading correction for feldspar IRSL dating - tests on samples in field saturation. Radiation Measurements 43: 786-790, 10.1016/j.radmeas.2008.01.021.

Kars RH, Busschers FS and Wallinga J, 2012. Validating post IR-IRSL dating on K-feldspars through comparison with quartz OSL ages. Quaternary Geochronology 12: 74-86, DOI 10.1016/j.quageo.2012.05.001.

Klasen N, Fiebig M, Preusser F, Reitner JM and Radtke U, 2007. Luminescence dating of proglacial sediments from the Eastern Alps. Quaternary International 164-165: 21-32, DOI 10.1016/j.quaint.2006.12.003.

Kreutzer S, Schmidt C, Fuchs MC, Dietze M, Fischer M and Fuchs M, 2012. Introducing an $\mathrm{R}$ package for luminescence dating analysis. Ancient TL 30(1): 1-8.

Lai ZP, Zöller L, Fuchs M and Brückner H, 2008. Alpha efficiency determination for OSL of quartz extracted from Chinese loess. $R a$ diation Measurements 43: 767-770, DOI 10.1016/j.radmeas.2008.01.022.

Lapp T, Jain M, Thomsen KJ, Murray AS and Buylaert J-P, 2012. New luminescence measurement facilities in retrospective dosimetry. Radiation Measurements 47: 803-808, DOI 10.1016/j.radmeas.2012.02.006.

Lomax J, 2009. Palaeodunes as archives of environmental change - A case study from the western Murray Basin (South Australia) based on optically stimulated luminescence (OSL) dating of single and multiple grains of quartz. Ph.D. Thesis, University of Cologne, Germany: 265pp.

Lowick SE, Trauerstein M and Preusser F, 2012. Testing the application of post IR-IRSL dating to fine grain waterlain sediments. Quaternary Geochronology $\quad 8: \quad 33-40, \quad$ DOI 10.1016/j.quageo.2011.12.003

Maroto J, Vaquero M, Arrizabalaga Á, Baena J, Baquedano E, Jordá J, Julià R, Montes R, van der Plicht J, Rasines P and Wood R, 2012. Current issues in late Middle Palaeolithic chronology: New assessments from Northern Iberia: The Neanderthal Home: spatial and social behaviours. Quaternary International 247: 15-25, DOI 10.1016/j.quaint.2011.07.007.

Martins AA, Cunha PP, Buylaert J-P, Huot S, Murray AS, Dinis P and Stokes M, 2010. K-feldspar IRSL dating of a Pleistocene river terrace staircase sequence of the Lower Tejo River (Portugal, western Iberia). Quaternary Geochronology 5: 176-180, DOI 10.1016/j.quageo.2009.06.004.

Martínez C, 1997. El yacimiento musteriense de Cueva Antón (Mula, Murcia) (The Mousterian site of Cueva Antón (Mula, Murcia)). Memorias de Arqueología de la Región de Murcia 6: 18-47 (in Spanish).

Medialdea A, Thomsen KJ, Murray AS and Benito G, 2014. Reliability of equivalent-dose determination and age-models in the OSL dating of historical and modern palaeoflood sediments. Quaternary Geochronology 22: 11-24, DOI 10.1016/j.quageo.2014.01.004.

Meese DA, Gow AJ, Alley RB, Zielinski GA, Grootes PM, Ram M, Taylor KC, Mayewski PA and Bolzan JF, 1997. The Greenland Ice Sheet Project 2 depth-age scale: Methods and results. Journal of Geophysical Research 102(C12): 26411-26423, DOI 10.1029/97JC00269.

Mejdahl V, 1979. Thermoluminescence dating: beta attenuation in quartz grains. Archaeometry 21: 61-73, DOI 10.1111/j.14754754.1979.tb00241.x. 
Murray AS and Wintle AG, 2000. Luminescence dating of quartz using an improved single-aliquot regenerative-dose protocol. Radiation Measurements 32: 57-73, DOI 10.1016/S1350-4487(99)00253-X.

Murray AS and Wintle AG, 2003. The single aliquot regenerative dose protocol: potential for improvements in reliability. Radiation Measurements 37: 377-381, DOI 10.1016/S1350-4487(03)000532.

Murray AS, Thomsen KJ, Masuda N, Buylaert JP and Jain M, 2012. Identifying well-bleached quartz using different bleaching rates of quartz and feldspar luminescence signals. Radiation Measurements 47: 688-695, DOI 10.1016/j.radmeas.2012.05.006.

Nathan RP, Thomas PJ, Jain M, Murray AS and Rhodes EJ, 2003. Environmental dose rate heterogeneity of beta radiation and its implications for luminescence dating: Monte Carlo modelling and experimental validation. Radiation Measurements 37: 305-313, DOI 10.1016/S1350-4487(03)00008-8.

Olley JM, Roberts RG and Murray AS, 1997. Disequilibria in the uranium decay series in sedimentary deposits at Allen's cave, Nullarbor Plain, Australia: Implications for dose rate determinations. Radiation Measurements 27: 433-443, DOI 10.1016/j.jhevol.2013.01.006.

Olley JM, Caitcheon G and Murray AS, 1998. The distribution of apparent dose as determined by optically stimulated luminescence in small aliquots of fluvial quartz: implications for dating young sediments. Quaternary Geochronology 17: 1033-1040, DOI 10.1016/S0277-3791(97)00090-5.

Poolton NRJ, Wallinga J, Murray AS, Bulur E and Bøtter-Jensen L, 2002. Electrons in feldspar I: on the wavefunction of electrons trapped at simple lattice defects. Physics and Chemistry of Minerals 29: 210-216, DOI 10.1007/s00269-001-0217-3.

Prescott JR and Hutton JT, 1988. Cosmic ray and gamma ray dosimetry for TL and ESR. Nuclear Tracks and Radiation Measurements 14(1/2): 223-227, DOI 10.1016/1359-0189(88)90069-6.

Prescott JR and Hutton JT, 1994. Cosmic ray contributions to dose rates for luminescence and ESR dating: large depths and long-term time variations. Radiation Measurements 23(2/3): 497-500, DOI 10.1016/1350-4487(94)90086-8.

Preusser F, Andersen BG, Denton GH and Schlüchter C, 2005. Luminescence chronology of Late Pleistocene glacial deposits in North Westland, New Zealand. Quaternary Science Reviews 24: 22072227, DOI 10.1016/j.quascirev.2004.12.005.

Preusser F, Ramseyer K and Schlüchter C, 2006. Characterisation of low OSL intensity quartz from the New Zealand Alps. Radiation Measurements 41: 871-877, DOI 10.1016/j.radmeas.2006.04.019.

Reimann T, Tsukamoto S, Naumann M and Frechen M, 2011. The potential of using K-rich feldspars for optical dating of young coastal sediments - A test case from Darss-Zingst peninsula (southern Baltic Sea coast). Quaternary Geochronology 6: 207222, DOI 10.1016/j.quageo.2010.10.001.

Reimann T, Thomsen KJ, Jain M, Murray AS and Frechen M, 2012a. Single-grain dating of young sediments using the pIRIR signal from feldspar. Quaternary Geochronology 11: 28-41, DOI 10.1016/j.quageo.2012.04.016.

Reimann T,Lindhorst S, Thomsen KJ, Murray AS and Frechen M, 2012b. OSL dating of mixed coastal sediment (Sylt, German Bight, North Sea). Quaternary Geochronology 11: 52-67, DOI 10.1016/j.quageo.2012.04.006.

Rhodes EJ, 2007. Quartz single grain OSL sensitivity distributions: implications for multiple grain single aliquot dating. Geochronometria 26: 19-29, DOI 10.2478/v10003-007-0002-5.

Rittenour TM, 2008. Luminescence dating of fluvial deposits: applications to geomorphic, palaeoseismic and archaeological research. Boreas 37: 613-635, DOI 10.1111/j.1502-3885.2008.00056.x.

Roberts HM, 2012. Testing Post-IR IRSL protocols for minimising fading in feldspars, using Alaskan loess with independent chronological control. Radiation Measurements 47: 716-724, DOI 10.1016/j.radmeas.2012.03.022.

Roberts RG, Galbraith RF, Yoshida H, Laslett GM and Olley JM, 2000. Distinguishing dose populations in sediment mixtures: a test of single-grain optical dating procedures using mixtures of laboratory dosed quartz. Radiation Measurements 32: 459-465, DOI 10.1016/S1350-4487(00)00104-9.

Smedley RK, Duller GAT, Pearce NJG and Roberts HM, 2012. Determining the K-content of single-grains of feldspar for luminescence dating. Radiation Measurements 47: 790-796, DOI 10.1016/j.radmeas.2012.01.014.

Sohbati R, Murray AS, Buylaert J-P, Ortuño M, Cunha PP and Masana E, 2012. Luminescence dating of Pleistocene alluvial sediments affected by the Alhama de Murcia fault (eastern Betics, Spain) - a comparison between OSL, IRSL and post-IR IRSL ages. Boreas 41: 250-262, DOI 10.1111/j.1502-3885.2011.00230.x.

Specht E, 2012. The best known packings of equal circles in a circle. WEB site: <http://www.packomania.com>. Accessed 2014 July 24.

Spooner NA, 1992. Optical dating: preliminary results on the anomalous fading of luminescence from feldspars. Quaternary Science Reviews 11: 139-145, DOI 10.1016/0277-3791(92)90055-D.

Spooner NA, 1994. The anomalous fading of infrared-stimulated luminescence from feldspars. Radiation Measurements 23: 625-632, DOI 10.1016/1350-4487(94)90111-2.

Spooner NA and Allsop A, 2000. The spatial variation of dose-rate from ${ }^{90} \mathrm{Sr} /{ }^{90} \mathrm{Y}$ beta sources for use in luminescence dating. Radiation Measurements 32: 49-55, DOI 10.1016/S1350-4487(99)00252-8.

Stone AEC and Bailey RM, 2012. The effect of single grain luminescence characteristics on single aliquot equivalent dose estimates. Quaternary Geochronology 11: 68-78, DOI 10.1016/j.quageo.2012.03.014.

Thiel C, Buylaert J-P, Murray A, Terhorst B, Hofer I, Tsukamoto S and Frechen M, 2011. Luminescence dating of the Stratzing loess profile (Austria) - Testing the potential of an elevated temperature post-IR IRSL protocol. Quaternary International 234: 23-31, DOI 10.1016/j.quaint.2010.05.018.

Thomsen KJ, Murray AS and Bøtter-Jensen L, 2005. Sources of variability in OSL dose measurements using single grains of quartz. Radiation Measurements 39: 47-61, DOI 10.1016/j.radmeas.2004.01.039.

Thomsen KJ, Murray AS, Bøtter-Jensen L and Kinahan J, 2007. Determination of burial dose in incompletely bleached fluvial samples using single grains of quartz. Radiation Measurements 42: 370379, DOI 10.1016/j.radmeas.2007.01.041.

Thomsen KJ, Bøtter-Jensen L, Jain M, Denby PM and Murray AS, 2008a. Recent instrumental developments for trapped electron dosimetry. Radiation Measurements 43: 414-421, DOI 10.1016/j.radmeas.2008.01.003.

Thomsen KJ, Murray AS, Jain M and Bøtter-Jensen L, 2008b. Laboratory fading rates of various luminescence signals from feldsparrich sediment extracts. Radiation Measurements 43: 1474-1486, DOI 10.1016/j.radmeas.2008.06.002.

Thomsen KJ, Murray AS and Jain M, 2011. Stability of IRSL signals from sedimentary K-feldspar samples. Geochronometria 38(1): 113, DOI 10.2478/s13386-011-0003-z.

Vasiliniuc S, Vandenberghe DAG, Timar-Gabor A, Panaiotu C, Cosma $\mathrm{C}$ and van den Haute $\mathrm{P}, 2012$. Testing the potential of elevated temperature post-IR IRSL signals for dating Romanian loess. Quaternary Geochronology $10: \quad 75-80, \quad$ DOI 10.1016/j.quageo.2012.02.014

Vegas J, Ruiz-Zapata B, Ortiz JE, Galán L, Torres T, García-Cortés A, Gil-García MJ, Pérez-González A and Gallardo-Millán JL, 2010. Identification of arid phases during the last $50 \mathrm{cal}$. ka BP from the Fuentillejo maar-lacustrine record (Campo de Calatrava Volcanic Field, Spain). Journal of Quaternary Science 25(7): 1051-1062, DOI 10.1002 /jqs. 1262 .

Wallinga J, 2002. Optically stimulated luminescence dating of fluvial deposits: a review. Boreas 31: 303-322, DOI 10.1111/j.15023885.2002.tb01076.x.

Wallinga J, Bos AJJ, Dorenbos P, Murray AS and Schokker J, 2007. A test case for anomalous fading correction in IRSL dating. Quaternary Geochronology 2: 216-221, DOI 10.1016/j.quageo.2006.05.014. 
Wintle AG, 1997. Luminescence dating: laboratory procedures and protocols. Radiation Measurements 27(5/6): 769-817, DOI 10.1016/S1350-4487(97)00220-5.

Wintle AG and Murray AS, 2006. A review of quartz optically stimulated luminescence characteristics and their relevance in singlealiquot regeneration dating protocols. Radiation Measurements 41: 369-391, DOI 10.1016/j.radmeas.2005.11.001.

Wood RE, Barroso-Ruíz C, Caparrós M, Jordá-Pardo JF, Santos BG and Higham TFG, 2013. Radiocarbon dating casts doubt on the late chronology of the Middle to Upper Palaeolithic transition in southern Iberia. Proceedings of the National Academy of Sciences of the United States of America 110(8): 2781-2786, DOI 10.1073/pnas.1207656110.

Yoshida H, Roberts RG, Olley JM, Laslett GM and Galbraith RF, 2000. Extending the age range of optical dating using single 'supergrains' of quartz. Radiation Measurements 32: 439-446, DOI 10.1016/S1350-4487(99)00287-5.
Zhao $\mathrm{H}$ and $\mathrm{Li} \mathrm{SH}, 2005$. Internal dose rate in $\mathrm{K}$-feldspar grains from radioactive elements other than potassium. Radiation Measurements 40: 84-93, DOI 10.1016/j.radmeas.2004.11.004.

Zilhão J and Villaverde V, 2008. The Middle Paleolithic of Murcia. Treballs d'Arqueologia 14: 229-248.

Zilhão J, Angelucci DE, Badal-García E, d'Errico F, Daniel F, Dayet L, Douka K, Higham TFG, Martínez-Sánchez MJ, Montes-Bernárdez R, Murcia-Mascarós S, Pérez-Sirvent C, Roldán-Garcíaj C, Vanhaerenk M, Villaverdec V, Wood R and Zapata J, 2010. Symbolic use of marine shells and mineral pigments by Iberian Neandertals. Proceedings of the National Academy of Sciences of the United States of America 107(3): 1023-1028, DOI 10.1073/pnas.0914088107.

Zilhão J, Angelucci DE, Burow C, Hilgers A, Kehl M, Villaverde V, Wood R and Zapata J, 2012. From Late Mousterian to Evolved Aurignacian: New Evidence for the Middle-to-Upper Paleolithic Transition in Mediterranean Spain. Abstracts European Society for the Study of Human Evolution, Bordeaux: 176. 